\title{
Conflicted Minds: Recalibrational Emotions Following Trust-based Interaction
}

\author{
Eric Schniter ${ }^{\mathrm{a}, *}$ \\ Roman M. Sheremeta ${ }^{b}$ \\ Timothy Shields ${ }^{b}$ \\ ${ }^{a}$ Economic Science Institute, Chapman University \\ One University Drive, Orange, CA 92866, U.S.A. \\ ${ }^{\mathrm{b}}$ Argyros School of Business and Economics, Chapman University, \\ One University Drive, Orange, CA 92866, U.S.A.
}

\begin{abstract}
Consistent with a modular view of the mind, both short-sighted and long-sighted programs may be simultaneously active in the mind and in conflict with one another when individuals face choice dilemmas in trust-based economic interactions. Recalibrational theory helps us identify the adaptive design features shared among subsets of superordinate emotion programs. According to this design logic and the computation of adaptive problem features produced by Trust games, we predict the activation of emotions after Trust games. While this study successfully predicts reports of twenty distinct emotional states, further studies are needed to demonstrate ultimate recalibrational functions of emotions.
\end{abstract}

JEL Classifications:

Keywords: emotions, recalibrational theory, modularity, Trust game, experiments

* Corresponding author (email): schniter@ chapman.edu

We thank Rob Kurzban for helpful feedback and Chapman University and the Economic Science Institute for research support. Any errors are ours. 


\section{Introduction}

When one is confronted with a dilemma, there is some sort of internal conflict over how to pursue alternative outcomes that cannot be simultaneously fulfilled at their maxima. Trust-based interactions, such as in the Trust game (Berg et al., 1995), present such a dilemma to both the potential trustor and the trustee. The potential trustor must decide whether to pursue his short-term goal of immediate and certain material gains - maximally achieved by keeping his endowment, or else to pursue his long-term goal of developing a trust-based reciprocal exchange relationship - maximally achieved by ceding his endowment to the trustee stranger and thereby demonstrating trust. A trustor might transfer his money to a stranger because, knowing that it will be tripled before the stranger receives it, he expects the stranger will reciprocate and transfer back more money than the original endowment amount. Alternatively, the trustor might transfer his money to a stranger because he holds no expectations, but wishes to gather reputational information about the stranger's propensity towards trustworthy reciprocal exchange, which he can use to form expectations - on which he will base future interactions. Likewise, the trustee, having received a multiplied transfer of funds from the trustor, must decide whether to pursue her short-term goal of immediate material gains by keeping her funds, or else she can pursue her long-term goal of developing a trust-based reciprocal exchange relationship ${ }^{1}$ by transferring back an amount greater than what the trustor originally transferred and thereby demonstrating her trustworthiness. Adaptive problems such as these, modeled by the Trust game, are best solved by the simultaneous activation of both short-sighted and long-sighted programs ${ }^{2}$.

Normative accounts of decision making (e.g., von Neumann \& Morgenstern, 1944) argue that rational agents should pursue the best alternative by comparing costs and benefits of all outcomes. If decision makers always made the best choices by accurately evaluating all possible cost-benefit tradeoffs, there would be little value to ex-post emotional feedback. It is rarely the case that we have enough information, mental resources, or time to evaluate all outcomes when presented with a decision task (Simon, 1987; Todd, 2001, Mellers et al., 2001). In fact, under uncertainty, the resulting value of a

\footnotetext{
${ }^{1}$ While we study a single, anonymous interaction, we believe trust and reciprocity are rooted in a complex set of social interactions, experiences, and evolved computational psychology that integrate information and apply our gathered knowledge. Every opportunity to show trust and trustworthiness builds the stock of reputational information that people can potentially capitalize on or computationally apply to contextualized interactions. In the trust game, trustors who make trustbased choices not only discover consequent effects on their payoffs, they also gain information about the trustworthiness of trustees. Reputational information gained from one-shot anonymous interactions bears value in its own right, as part of a set of sampled experiences, it contributes to the formation of contextualized "norms" that can be strategically applied in future trust and investment games, or in other potential interactions or applications.

${ }^{2}$ This terminology, which comes from computational science, refers to neural circuits in the brain/body which process input information and accordingly cause outputs either in the informational form of internal regulatory variables and feedback (reused as input by programs) or behavior.
} 
choice outcome may be unknown and quite relative (Ketelaar \& Clore, 1997). It is when decision outcomes and their consequences are finally realized that recalibrational emotions are activated (Zeelenberg \& Beattie, 1997; Zeelenberg et al., 1998) ${ }^{3}$. Take for example a trust-based investment. A trustor may have learned from a collection of experiences in environment A that trust-based investments tend to produce profitable returns. In a novel environment B the trustee may optimistically expect similar opportunities as in A, but due to a lack of experience in environment B may not be as certain as to whether investments in trustees there will actually produce profitable returns. Not investing in B will never lead to profits as in A, so probative investment will at least produce a sampling experience. Thus, if a trustee in environment B is invested in and acts opportunistically, the trustee is best off if he can at least learn from the experience. The ex-post feedback that emotions provide, and their ability to recalibrate both self and other to improve conditions, contributes to the experience-based learning and recalibration process which is useful when taking advantage of opportunities in uncertain environments.

Divorced from their application, emotions do not appear to be cognitive tools, but instead may appear as flaws of human nature that interfere with rationality (Rand, 1964; Sherer, 1984; Elster, 1995). However, when known dilemmas are re-encountered and the emotions they previously activated are integrated into a decision calculus (e.g. Ketelaar \& Au, 2003), we see evidence for the specially designed recalibrational function of emotions. As such, the value of emotions activated after experiences is that they lead to a recalibration of others (to better engage in beneficial interactions), they lead to better informed decision processes (in self or others), and they contribute to the cultivation of self control and wisdom (Heckhausen \& Schulz, 1995; Haselton \& Ketelaar, 2006).

In this paper, we take an adaptationist perspective (Barkow et al., 1992) based on the assumption that the mind is best understood not as a general purpose computer, but as containing a multitude of evolved problem solving mechanisms designed through a process of natural selection to each solve particular subsets of recurrent problems. Different adaptive problems have required different and unique solutions (Barrett, 2005) and emotions appear to be coordinated systems of responses that have been selected for over evolutionary history because they increased fitness by solving specific problems (see Plutchik, 1980; Plutchik \& Kellerman, 1980; Nesse, 1990; Cosmides \& Tooby, 2000). A modular view of the cognitive mechanisms governing our choice process in economic decision dilemmas posits that both short-sighted programs and long-sighted programs exist; they are

\footnotetext{
${ }^{3}$ For an alternative account see Mellers \& McGraw (2001) who propose that prior to executing decisions, sets of anticipated emotions may be simulated and their hypothetical magnitudes compared. We suspect that these anticipated emotions are consequences of mental simulations (thought experiments) of how choices in decision dilemmas produce results.
} 
simultaneously active in the mind, and often in conflict with one another (Kurzban, 2010).

Superordinate programs like emotions appraise historical outcomes, need states, opportunity contexts, expectations, and forecasted consequences, for the purpose of selective regulation of simultaneously active and competing programs. Emotions regulate internally competing programs by recruiting the service of psychological and physiological mechanisms that ultimately lead to recalibration of self, another, or both self and other (Levenson, 1999; Cosmides \& Tooby, 2000; Tooby et al., 2008).

To test the recalibrational theory of emotions we designed an experiment based on the Trust game of Berg et al. (1995), where subjects act either as a trustor or as a trustee. In this game, the potential trustor receives an endowment of $\$ 10$ and can send any portion of it to trustee, with the amount sent tripled on the way. The trustee then decides how much to send back. Following the Trust game we administered a 20 item emotional status survey. We find ample evidence for the mixed emotional states that we predict to be activated by competing cognitive programs in our "conflicted minds". This evidence provides strong support for the theory that recalibrational emotions are activated in a patterned response to the problems produced by the results of trust-based interactions.

\section{Recalibrational Theory of Emotions}

\subsection{Short-Sighted and Long-Sighted Programs}

Our recalibrational theory of emotions hinges on a cognitive model including short-sighted and long-sighted programs that each respond to fundamental adaptive problems. When these programs are dually activated by the presence of these problems (such as in the Trust game), they enter into conflict, implying that neither program can fully achieve its goal due to the other's interference effects. This state of conflict between competing programs results in the activation of "negative" emotions, and at high levels of output, these negative emotions can bring about disastrous or self-destructive outcomes (Cosmides \& Tooby, 2000; de Catanzaro 1980, 1991). In their extremes, negative emotions reduce life-preserving motivations like appetite, hygiene maintenance, or the desire for safety, and can increase the risk of coronary heart disease by inducing or promoting inflammation (Danner et al., 2003). An emotional system, employed by the short and long-sighted programs, computationally assesses and manages the conflict through a mix of both positive and negative emotional outputs: homeostatic regulation, reinforcement, and targeted deregulation.

Short-sighted programs are designed to act in an expedient way (e.g. by processing only the minimum critical information for activation) that will seize present and certain opportunities before they are foregone or the possibility of seizing them becomes less certain or riskier. Unless there is an 
immediate, short-term reward to be gained from cooperating, short-sighted programs are not designed to cede resources or concern themselves with delayed reputational consequences. Short-sighted programs are primed by any context, history, or stimulus triggering awareness that there are opportunities available for quick and immediate rewards. In accordance with a time discounting process that is well documented in humans (see Hernstein, 1970; Loewenstein, 1987), short-sighted programs often generate hedonic feedback that gains are intrinsically rewarding and that losses are aversive. While we do not expect short-sighted programs to prefer uncertain investments, we do expect short-sighted programs to produce positive feedback once they register gains produced by trust-based investment relationships.

Long-sighted programs are designed to pursue the promise of risk buffering benefits, provided over the long-term, by preferring the pursuit of reliable exchange relationships and investments over immediate rewards. In calculating the promise of long-term rewards from exchange relationships or investments, long-sighted programs concern themselves with reputations (social investments) of trust and trustworthiness. Over the course of human evolutionary history, interactions with specific others were likely followed up by further interactions with those same individuals. Among hunter-gatherers, who subsist, organize, and socialize much like our human ancestors did for more than $99 \%$ of human history, most interactions are frequent, among people known and related by blood or marriage (e.g. see Hill et al., 2011), and organized into a three-generational family structure (Kaplan et al., 2009). In extant forager populations, the human family continues to be a principal nexus of resource exchange (Kelly, 1983).

This highly social and cooperative lifestyle, which characterizes our human ancestry, led to selection for a long-sighted, pro-social program, capable of not only managing conflict with a short sighted-program at work within self and others, but also capable of producing favorable social norms through the use of social emotions and morals.

Several theorists including moral philosophers (Hume, 1740; Smith, 1759), moral psychologists (Kohlberg, 1971, Haidt, 2003a; Ketelaar, 2006) evolutionary biologists (Darwin, 1872, Trivers, 1971, Nesse, 1990), and economists (Hirschleifer, 1987; Frank, 1988) have identified a set of emotions among humans designed to reinforce socially appropriate behavior or recalibrate self and others towards socially desirable behavior. These social emotions are activated by a long-sighted program designed to pursue and cultivate reciprocal exchange relationships and one's efficient integration into society. Effectively, the emotions exclusively produced by the long-sighted program induce commitments to long-term exchange relationships, despite the "commitment" problem (Frank, 
1988) presented by the interests of the short-sighted program: that immediate rewards are highly attractive and thus incentivize against the pursuit of long-term rewards.

We suggest that the experience of certain emotions, such as feeling believable and proud in the context of social exchange dilemmas, is an example of the long-sighted program confirming to itself that its calibration (relative to the short-sighted program) was consistent with achieving its goal. Likewise, when one behaves in a way that would harm one's positive reputation in the adaptive ancestral environment, some form of post-decision regret activated by the long-sighted program may provide a "feeling" that, at the next decision juncture, serves to motivate a stronger pursuit of longterm rewards (Zeelenberg, 1999; Zeelenberg et al., 2008). We suggest that feeling guilty and ashamed in the context of these social exchange interactions is one example of the various ways that a longsighted program employs emotions to coerce a downregulation of the short-sighted program.

Recognizing that the Trust game presents participants with choice dilemmas between alternatively pursuing short-term rewards or else acting in a way consistent with behavior necessary for long-term rewards from reciprocal exchange, we evaluate evidence indicating whether economic decisions and interactions in a Trust game are reliable predictors of subsequent emotional states. Evidence of predicted instantiation of this evolved psychology in laboratory-based experimental economic games helps us explain why humans, in these conditions, are regularly observed producing trusting, trustworthy, and cooperative behavior (Johnson et al., 2003).

\subsection{Positive and Negative Emotions}

Generally, an adaptationist and functional perspective (e.g. Cosmides \& Tooby, 2000; Buck, 1999; Tooby \& Cosmides 1990) of emotions argues that emotions facilitate behavioral regulation because they provide either positive or negative feedback which is used in updating the weighting of one's internal regulatory variables. Pleasant and unpleasant feelings, experienced as consequences of past actions or interactions, serve as either incentive or disincentive to motivate change from previous behavioral calibrations. Pleasant feelings (e.g. from happiness, contentment, pride, cheerfulness) are rewarding and incentivize approach behavior (Watson et al., 1999) or future continuation of the prior behavior or interaction that activated them (Carver \& Scheier, 1990), while unpleasant feelings (e.g. from sadness, aggravation, guilt, disgust, anger) are costly and motivate a change (Gray, 1971), whether through downregulated behavior, avoidance, or aggression.

In accord with affect-as-information (Ketelaar, 2006; Ketelaar \& Au, 2003) and benefit appraisal (Ellsworth \& Smith, 1988a, 1988b) approaches, positive emotions, in so far as their outputs 
are experienced consciously as affective states, indicate potential fitness benefits, while negative emotions indicate potential fitness costs. These categories of positive and negative emotions are crossculturally (e.g., Lutz, 1982; Osgood et al., 1975; Russell, 1983) interpreted by those experiencing them in desirability terms - valued as "good" or "bad", respectively. Zeelenberg et al. (2008) suggest that the effectiveness of emotions comes from the fact that they are "felt" hedonically". While it is very helpful to consider the consciously experienced positive or negative affective feedback which many emotions may provide, we recognize that, fundamentally, emotions are superordinate programs which coordinate and regulate the two key programs that are individually designed to solve specific adaptive problems evoked by Trust game scenarios. Negative emotions - activated by the output of programs which have failed to achieve their goals - tend to selectively target the competing programs, downregulating them in future dilemmas. Given that the subordinate programs which had failed their goals protest their position through emotional outputs and thereby attempt to gain traction, dominant programs need to hold their ground (or even increase their outputs) if they have successfully solved the problems they were designed to respond to. To do this, a successful program recruits positive emotions which effectively reinforce the recruiter or maintain homeostasis: taking necessary regulatory actions to increase outputs or maintaining the equilibrium between the successful program and the program (whether self and/or other's) which may act against its interests.

Thus, when competing programs are activated by a dilemma, a decision outcome, whether "successful" or not (from the achievement perspective of each of the competing programs), may result in a mix of both positive and negative emotions (Cacciopo, Gardner, Berntson, 1999). While the experience of mixed emotions has been evoked with wins and losses in the laboratory (Larsen, McGraw, Cacciopo, 2001; Larsen et al., 2004), it challenges our intuitions of singular internal interests

\footnotetext{
${ }^{4}$ Roots of this idea can be traced back to elements of Epicurean philosophy. Epicurus ( $341-270$ BC) taught that pleasure and pain are the measures of what is good and evil. Similarly, Damasio's (1994) "somatic marker hypothesis" argues that emotions are sensed corporally more than mentally (though Adam Smith (1759) maintained a contrary perspective, that "pleasures and pains of the mind" exert an even greater influence on behavior than do bodily feelings). That reliably informative feedback may be provided by states perceived as good or bad is an intuitively appealing idea; after all, intuitions about emotions are generally rooted in the thoughts or feelings that people are consciously aware of.

Nevertheless, insights from psychology and cognitive science have provided reason to caution against exclusive reliance on intuitive appeal as a justification for formulating cognitive models. An oft-quoted principle of evolutionary psychology thus states: "Consciousness is just the tip of the iceberg; most of what goes on in your mind is hidden from you. As a result, your conscious experience can mislead you into thinking that our circuitry is simpler than it really is." (Cosmides \& Tooby,
} 1997). 
and it challenges the consonance of a sane mind which we often attribute to a non-contradictory selfrepresentation ${ }^{5}$.

\subsection{Targets of Emotional Recalibration}

When we regard emotions as phenomena with underlying etiologies (James, 1890, p. 449) the most parsimonious taxonomy that emerges organizes emotions with respect to their shared functional features. Perhaps the binary division into positive and negative affect types is the simplest taxonomy of emotions (Tellegen et al., 1999) . Several theoreticians (Lerner \& Keltner, 2000, 2001; Van Kleef, de Dreu, \& Manstead, 2004) have argued that by moving beyond the more simplistic models of valence (or positive and negative affect) to models of design-specific emotions, we gain even greater explanatory power of how emotions affect behavior. We are sympathetic to the argument (e.g. Frank, 1988; Cosmides \& Tooby, 2000; Ketelaar \& Au, 2003, Haselton \& Ketelaar, 2006; Tooby et al., 2008) that specific emotions are designed to solve specific adaptive problems because by identifying designs specifics we can generate nuanced predictions. In considering the nature of adaptive decision problems encountered in trust-based interactions, we recognize that the outcomes of these decisions are contingent on not only self actions (according to the calibration of our internal programs), but also the actions of others (according to the calibration of their programs). As such, it is helpful to consider a typology of these adaptive problems in terms of their solutions: specifically, solutions arrived at via intrapersonal and/or interpersonal behavior regulation (e.g. see Bowlby, 1969; Levenson, 1999; Van Kleef et al., 2004; Butt et al., 2005). Below we discuss the distinction between intrapersonal emotions that may affect reinforcement, maintenance, or change of self behavior, and interpersonal emotions that may ultimately affect reinforcement, maintenance, or change of another's behavior.

\subsubsection{Intrapersonal Recalibration}

Emotions are ultimately designed to deal with the adaptive problem of program orchestration (Tooby \& Cosmides, 1990) - a problem which arises, as we have described above, by the simultaneous activation of competing programs within an individual's mind. To solve this adaptive problem, triggered emotions have been designed by natural selection to recruit the assistance of a number of

\footnotetext{
${ }^{5}$ People tend to not admit that they regularly grapple with internally conflicted motivations and that a state of mixed positive and negative emotion is a healthy equilibrium - that it is 'normal' to encounter one's self in such a state. Instead, people, religions, and now governments like Bhutan (Revkin, 2005; Larmer, 2008) pursue the maxim of happiness which they believe to be the healthiest state. Such a pursuit runs the risk of leading to unintended harm (e.g. Nesse, 1991; 2004).
} 
psychological and behavioral processes ${ }^{6}$ which are best suited for affecting a recalibration of targeted programs. When one's prior actions did not succeed in achieving an adaptive goal, emotions are activated and directed at self. These intrapersonal emotions function to motivate a recalibration (specifically a down-regulation) of the program responsible for one's prior actions. Some of these intrapersonal negative emotions may be activated by both short and long-sighted programs, while other negative emotions may be activated exclusively by only short-sighted or long-sighted programs. For example, guilt, an intrapersonal emotion activated exclusively by the long-sighted program, is a negative emotion proposed to help solve "commitment" problems (Frank, 1988). Guilt achieves this function by effectively recalibrating (i.e. downregulating) the dominant short-sighted program so as to effectively increase the value of delayed payoffs (such as from reciprocal exchange which produces demonstrable regard for another person's perspective) relative to immediate payoffs (that only show regard for self). As immediate payoffs decrease in magnitude (as a function of guilt felt), the costs of forgone long-term rewards looms larger in our minds.

\subsubsection{Interpersonal Recalibration}

Another way that emotions are designed to function is by regulating another individuals' programs in an effort to affect how they interact with one's self. For example, consider the gratitude emotion. Discovery that another has foregone short-term rewards in the pursuit of a long-term exchange relationship with one's self - for example by providing assistance, presents a fortunate opportunity but one that must be acknowledged, lest it appear that the goodwill relationship initiated by the other is taken for granted by self and not reciprocated in kind. If one is unprepared to reciprocate in some welcomed form directly after receiving a benefit, how can one signal or demonstrate willingness to reward the other? Several theorists have suggested that gratitude is an emotion designed for this adaptive problem (Tooby \& Cosmides, 2008; Lim et al., 2008).

Experimental evidence supports this functional account of gratitude (Gergen et al., 1975; Tesser et al., 1968; Algoe et al., 2008; Algoe \& Haidt, 2009; McCullough et al., 2001).

\footnotetext{
${ }^{6}$ Identification of a variety of these processes further informs proximate explanations of "how" emotions function, which we do not fully explore given the scope of this paper. We direct interested readers to the following: Levenson (1994, p.123) suggests that "Psychologically, emotions alter attention, shift certain behaviors upward in response hierarchies, and activate relevant associative networks in memory. Physiologically, emotions rapidly organize the responses of disparate biological systems including facial expression, somatic muscular tonus, voice tone, autonomic nervous system activity, and endocrine activity to produce a bodily milieu that is optimal for effective response." Similarly, Cosmides \& Tooby (2000, p. 93) suggest that an emotion can orchestrate competing programs via "effects on physiology, behavioral inclinations, cognitive appraisals, or feeling states, because it involves evolved instructions for all of them together, as well as other mechanisms distributed throughout the human mental and physical architecture."
} 


\subsubsection{Dual Intrapersonal and Interpersonal Recalibration}

A few emotions are designed to regulate dual targets: particular programs within one's self, and particular programs in others. Shame and embarrassment are emotions which may dually serve both self-directed and other-directed purposes. Generally speaking, the shared adaptive goal of shame and embarrassment is for one to preempt another's targeted inter-personal regulation of one's self by, instead, initiating self-imposed regulations with the functional equivalence of regulations that the other party might otherwise impose. For example, shame could preempt a disgust reaction in another if it preemptively leads to distancing one's self from the other, or alternatively, shame could preempt anger in another if it preemptively imposes costs on one's self. Likewise, the appeasement function of embarrassment may act remedially, effectively preempting the social conflict and aggression outputs from others, for example, such as when others experience anger as a consequence of one's rule violations (Keltner et al., 1997; de Jong, 1999). This class of dually intrapersonal and interpersonal emotions is unique in that, when activated, it recalibrates a targeted program within the self and in doing so affects a change that in turn downregulates the interpersonal emotions that would otherwise be activated in others.

\subsection{Predicting the Roles of Emotions}

Based on the functions of different types of emotions described above, we propose a specific functional classification for each of 20 emotions studied (see Table 1a), and produce operational definitions (see the online Appendix 1) according to the constellations of these shared features. This classification system allows us to identifying the positive and negative emotions that are in service of a short-sighted goal (of material gain) and/or the more long-sighted goal (of developing reciprocal exchange relationships). In our emotion definitions we recognize unique features of specific emotions and the specificity of conditions which are required to cue their activation. Our definitions are also chosen according to the functional features which we expect will be useful for statistically identifying emotions produced by a Trust game. Nesse (2004, p.1138) states that, while emotions have been selected for because of their ability to solve specific adaptive problems, “...there is no one to one correspondence between an emotion and a function. One emotion can serve multiple functions, and one function may be served by several different emotions." Consistent with Nesse, our functional classification of 20 emotions yields specific sets of multiple emotions that we expect to be activated for singular functional purposes. 
We next describe our experimental design and state predictions derived from the theory that potentially competing programs, each evolved to pursue a specific adaptive goal, recruit superordinate emotion programs to calibrate self and/or other, so as to optimize the pursuit of adaptive goals while reducing the internal conflicts which can arise in pursuit of such goals.

\section{Design, Predictions and Procedures}

\subsection{Quasi-Experimental Design}

We ran a basic Trust game in which the potential trustor received an endowment of $\$ 10$ and could send any portion of it to trustee, with the amount sent tripled on the way. The trustee then decided how much to send back. Following the Trust game we administered a 20 item $^{7}$ emotional status survey. Using this laboratory implementation of the Trust game, which engages participants in one-shot anonymous economic interactions, we investigated whether emotions were activated in a patterned and predicted way.

\subsection{Predictions}

Inspired by functional theories of social emotions (Trivers, 1981; Cosmides \& Tooby, 1989), Nesse (1990, p.275; 1999, p.458) made various predictions about how specific emotions mediating reciprocity would be activated by the 4 types of interaction patterns produced by a repeated Prisoner's Dilemma game. To our knowledge these predictions have not yet been tested. In this paper we take a similar natural-experiment approach and examine the relationship between emotions and the endogenous generation of antecedents based on participants' Trust game choice and interaction consequences. Like the Prisoner's Dilemma, the Trust game is another model for reciprocity that more specifically provides examples of trust-based investment and trustworthy reciprocity. We argue that even the one-shot Trust game provides participants familiar cues for identifying the kind of common cooperation problems that have regularly presented adaptive challenges over the course of human evolution. Given the ecological validity of the Trust game, and the assumption that participants are able to reflectively access and honestly report their emotional states, we expect to be able to reliably

\footnotetext{
${ }^{7}$ Most emotion researchers agree on the universality of at least 8 emotions, including anger, sadness, joy, fear, shame, pride, disgust, and guilt (e.g. see Ekman, 1992; Frijda, 1986; Izard, 1991). According to our recalibrational theory, a much larger set of emotions (including the 20 we examine) surely exists. While space does not permit a review of the many debates over how to define emotions, footnotes to the online Appendix 1 may serve interested readers as a guide to some of the literature offering additional or alternative perspectives.
} 
measure in the laboratory specific emotional responses that have conferred humans fitness benefits over the course of evolution.

Like Binmore (1998), who likened emotional strategies to computer programmed decision rules, we take a computational and logic-based approach to specifying the hypothesized design of emotions. While appraisal theoreticians (Ortony et al., 1988; Lewis, 1990; Haidt, 2003a, 2003b; Rozin et al, 1993) before us have toiled to uncover "antecedents" of emotions, no work that we are aware of has yet demonstrated under controlled conditions, how an endogenous generation of behavior leads to reliably predictable emotional states. We contribute to this endeavor, testing whether constellations of specific antecedents (the "A", "B", "C", and "D" weights produced by Trust game interaction; see Figure 1) are reliable situational elicitors of specific emotion responses according to a logic of how decision outcomes map onto the propositional structure of the long-term program (see Prediction 1) and the short-term programs' (see Prediction 2) emotion activation circuitry.

Prediction 1. Given that self's long-sighted program $\left(=_{L}\right)$ goal $_{L}$ is to develop successful exchange relationships, and given that successful exchange relationships are maximally achieved by deciding to demonstrate trust (via trust-based investment-transfer) or demonstrate trustworthiness (via reciprocation of investment plus profits on investment), while the other makes the complementary choice pursuant to goal $_{\mathrm{L}}$, four propositional structures activating recalibrational emotions pursuant to goal $_{L}$ are predicted based on self or other's decisions:

P1.1 IF self's decision contributes to goal $_{\mathrm{L}}$ THEN positive intra-personal emotions are activated.

P1.2 IF self's decision does not contribute to goal $\mathrm{L}_{\mathrm{L}}$ THEN exclusively long-sighted negative intrapersonal and exclusively long-sighted negative inter-personal emotions are activated.

P1.3 IF other's decision contributes to goal $\mathrm{L}_{\mathrm{L}}$ THEN positive inter-personal emotions are activated. P1.4 IF other decision does not contribute to goal $\mathrm{L}$ THEN negative inter-personal emotions (not including the exclusively long-sighted emotions) are activated.

Prediction 2. Given that self's short-sighted program $\left(=_{s}\right)$ goal $_{S}$ is to maximize immediate and certain material gains, four propositional structures activating recalibrational emotions pursuant to goal $_{S}$ are predicted based on self or other's decisions:

P2.1 IF self's decision contributes to goal $S$ THEN positive intra-personal emotions (not including the exclusively long-sighted emotions) are activated.

P2.2 IF self's decision does not contribute to goals THEN negative intra-personal emotions (not including the exclusively long-sighted emotions) are activated.

P2.3 IF other's decision contributes to ego's goals THEN positive inter-personal emotions are activated. 


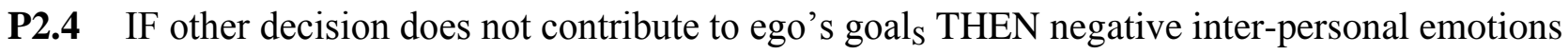
(not including the exclusively long-sighted emotions) are activated.

For illustration, we describe below how each of the "A", "B", "C", and " $\mathrm{D}$ " weights produced by Trust game decisions and interactions correspond to situational elicitors of a few of the many specific emotion responses possible (our examples are not exhaustive of the complete set of emotions predicted by the weights). For the complete specifications of emotions according to situational elicitors produced by the Trust game, see Tables $1 \mathrm{~b}$ and $1 \mathrm{c}$. Tables $1 \mathrm{~b}$ and $1 \mathrm{c}$ detail the additive combinations of the weights (derived from the computational model seen in Figure 1) contributing to predicted values of emotion subsets (U1-U6) for trustor and trustee. This combined functional framework of emotional response (represented in Table 2 and Figure 3) has been constructed based on the hypothesized adaptive functions of the defined emotions and the nature of the adaptive problems presented by Trust game outcomes.

When the " $\mathrm{A}$ " is heaviest the trustee has transferred-back the greatest amount of trustor's invested endowment possible. The "A" weight quantifies the trustee's reciprocal behavior by providing a measure of the amount of invested endowment that is returned in a Trust game interaction. A heavy "A" weight contributes to the trustee's long-sighted program activating more proud and believable emotions, while the short-sighted program simultaneously activates aggravation, frustration, and depression to recalibrate the competing long-sighted program. Likewise, a heavy " $\mathrm{A}$ " weight will contribute to emotion activation in the trustor. For example, a heavy " $\mathrm{A}$ " weight causes both of the trustor's long and short-sighted programs' to activate an appreciation emotion targeting the trustee.

When the "B" weight is heaviest the trustee has transferred-back nothing and opportunistically kept the greatest amount of the trustor's invested endowment possible. While the "B" weight is limited by the amount of endowment invested, it quantifies the amount of opportunistic behavior demonstrated by the trustee who does not return invested endowment in a Trust game interaction. A heavy "B" weight produced by a Trust game interaction contributes to the long-sighted program in trustees activating guilt, shame and embarrassment to recalibrate the competing short-sighted program. Likewise, a heavy "B" weight will contribute to both the long and short-sighted programs in trustors activating anger ${ }^{8}$ and aggravation.

\footnotetext{
${ }^{8}$ When the trustor has made himself financially vulnerable by allocating resources to another (a failure of the short-sighted program), yet subsequent to the investment it is discovered that the other hasn't reciprocated and instead acted more opportunistically (a failure of the long-sighted program), an anger response is produced. Self-directed anger activated by the short-sighted program may recalibrate the long-sighted program to not invest in an untrustworthy. Anger motivates one to either impose costs on or restrict benefits to the untrustworthy other so that, as a consequence, they will apply a
} 
When the "C" weight is heaviest the trustor has demonstrated no trust, invested nothing, and kept the greatest portion of her endowment possible. A heavy "C" weight - produced entirely by a trustor's decision to not invest endowment in the Trust game - contributes to the long-sighted program in trustors activating guilt, shame and embarrassment to recalibrate the competing short-sighted program. Likewise, a heavy "C" weight will contribute to both the long and short-sighted programs in trustees activating disgust and frustration.

When the " $D$ " weight is heaviest the trustor has invested all of her endowment and the trustee has transferred-back nothing and opportunistically kept the greatest amount of income possible. A heavy "D" weight is a dual-product of the amount of income that a trustor's investment creates and the amount of this income that a trustee decides not to transfer back in a Trust game. A heavy " $\mathrm{D}$ " weight will contribute to activation of a negative surprise reaction by the trustor's short-sighted who expects monetary gains from returns on large investments. From the selfish perspective of the trustee's shortsighted program, a heavy "D" weight corresponds to an extremely profitable and generally unexpected, but seized, "opportunity". The short-sighted program in the trustee who has fully exploited such an opportunity will activate happiness while also activating positive surprise and appreciation targeting the long-sighted program in trustors that made the opportunity possible.

\subsection{Experimental Procedures}

The experiment was conducted at Chapman University's Economic Science Institute. Subjects were recruited from a standard subject pool consisting primarily of undergraduate students and randomly assigned to trustor and trustee roles. Subjects interacted with each other anonymously over a local computer network. The experiment was programmed and conducted using z-Tree (Fischbacher, 2007). The computers were placed within individual cubicles in such a way that all subjects could only view their own computer screen.

The four sessions, each lasting approximately thirty-five minutes, consisted of 18 to 24 subjects and were sequenced as follows. An experimenter read the instructions aloud while each subject followed along with their own copy of the instructions. The instructions explained the experimental procedures and payoffs used in the experiment (instructions are available in the online Appendix 2). After finishing the instructions, subjects were given five minutes to write down their answers to several questions to ensure that they understood the instructions. Subjects' answers remained confidential to

restrictive counterweight to their previously dominant short-sighted program and thereby change their tendency away from favoring short-term over long-term benefits should a repeated interaction present itself. 
other subjects. After subjects completed the quiz, the experimenter distributed a printed copy of the correct quiz answers. The experimenter answered in private any questions regarding the experiment procedures.

Each subject was told their role, labeled person 1 for the trustor and person 2 for the trustee. The trustor entered how much of $\$ 10$ they wished to send to the trustee. Afterwards the trustee entered how much of the income (i.e., the tripled investment) received to return the trustor. Using computers, participants completed a 20 item survey ${ }^{9}$ with nearly balanced sets of positive (9) and negative (10) emotions (one of the 20 emotions, "surprised", we consider both positive and negative), in which they reported the status of various emotions (on a 5 point scale labeled (1) very slightly or not at all, (2) a little, (3) moderately, (4) quite a bit, (5) extremely) consequent on their decisions, game interactions, and resulting outcomes.

Each subject was paid $\$ 7$ for participation and the payoffs from the Trust game. Each participant individually signed and dated a payment receipt form and received payment. On average subjects earned $\$ 10.31$ in addition to their payment for participation.

\section{Results}

We find no significant differences between the four sessions and report the joint results of all 90 subjects. Figure 2 displays the scatter plot of the amount sent and the amount sent back. There is substantial variability in individual behavior. On average, trustors sent $\$ 5.31$ and received $\$ 5.34$ back from the trustees, resulting in profits of $\$ 10.04$ and $\$ 10.57$, respectively. These results are consistent with previous findings of Berg et al. (1995).

\subsection{Regression Analysis of Individual Emotions}

Table 2 provides the set of predictions about how interactions based on trustee and trustor behaviors activate different emotions. We test these predictions applying linear regression analysis separately for each emotion. Results of this estimation are shown in Table 3. Each row in the table represents a separate emotion as a dependent variable. As independent variables we use the weights

\footnotetext{
${ }^{9}$ To avoid experimenter demand effects that might result by soliciting reports on only a few select emotional states commonly ascribed to failed trust-based interactions (i.e. anger and guilt) and identified in the literature (e.g. Ketelaar \& $\mathrm{Au}, 2003$ ), we constructed a survey of positive and negative emotional states, based on the Positive and Negative Affect Scale (PANAS), a 20-item self-report measure of positive and negative emotions developed by Watson et al. (1988) which has been demonstrated across a large non-clinical sample to be a reliable and valid measure of these emotional states (Crawford \& Henry, 2004).
} 
predicted by the theory. The first five columns are estimated for trustors and the last five columns are estimated for trustees.

Overall, we find that most of the emotions are well predicted by the theory. All emotions of trustor are significantly affected by at least one of the weights predicted by the theory. Specifically, 23 out of 25 weights are significant and have correct signs. For trustee, emotions are also significantly impacted by the weights, with 26 out 36 being significant and having correct signs. The one emotion that is not well predicted by the theory is surprised. This is not entirely unexpected, since many theorists (e.g. Ortony et al., 1988; Ortony \& Turner, 1990) have argued that "surprise" may not even qualify as an emotion as it could be either positively or negatively valenced - a source of confusion that may also contribute to participants' difficulty uniformly interpreting this label.

A simple linear regression analysis in Table 3 shows that the results of the experiment provide strong support for our theoretical predictions. It is important to emphasize, however, that simple regression analysis performed separately for each emotion does not account for the fact that emotions can be activated simultaneous. As we suggest, sets of emotions can operate jointly as a unified system. Therefore, error terms in each linear regression may be correlated. To correct for this correlation, we estimate seemingly unrelated regressions for all surveyed emotions, instead of separate regressions for each emotion. ${ }^{10}$ Table 4 reports results of this estimation. Note that, after accounting for the correlation of error terms, we find emotions continue to be well predicted by the theory. Moreover, assessing the predictive significance of weights, we find four cases of improved significance for trustor, and six cases of improved significance for trustee. Therefore, we conclude that emotional responses of trustors and trustees, following Trust game interactions, are well predicted by our theory.

\subsection{Factor Analysis}

Despite the cataloguing of almost countless emotions (e.g. Averill's (1975) Semantic Atlas of Emotional Concepts lists 558 words) and the impression that these emotions blend seamlessly into one another, the recalibrational theory of emotions suggests that we should be able to distinguish sets of emotions "by their severally appropriate objective stimuli [rather] than by their conscious or subjective tone" (James, 1890). Over the past century, theorists (e.g., Cattell, 1946; Burt, 1950; Guilford \& Zimmerman, 1956; Plutchik, 1980) have explored the analysis of underlying (latent) factor sets among the multitude of proposed emotions. Below, we also consider evidence for latent factor sets.

\footnotetext{
${ }^{10}$ Seemingly unrelated regression equations is a generalization of a linear regression model that consists of several regression equations, each having its own dependent variable and potentially different sets of exogenous explanatory variables.
} 
The Kaiser-Meyer-Olkin (KMO) measure of sampling adequacy provides an index (between 0 and 1) of the proportion of variance among the variables that might be indicative of latent factors. The overall KMO measure is 0.73 and 0.84 for the trustor and trustee, respectively. Half of the measures had scores greater than 0.8 (which Kaiser (1974) suggested as 'meritorious'). Consistent with the model, surprised had a score below 0.50 for both trustor and trustee, suggesting it is not behaving in the explainable manner that other emotions are.

We thus use factor analysis to examine the reliability of data on emotional states beginning with assessment of a single factor model based on emotion valence (i.e. positive or negative). Traditionally, PANAS scales have claimed to provide independent measures of positive and negative affect (see for example Costa \& McCrae, 1980). To exam the validity of this claim, we conducted item analyses on the 20 items hypothesized to assess (9) positive and (10) negative emotional states among our subjects. Positive emotions show positive correlation with all positive emotions (all of 36 correlations). Some, but not all, negative emotions show a positive correlation with other negative emotions (40/45 correlations). Between negative and positive emotions we see five positive correlations: four of which are for guilty (with secure, content, happy, and triumphant), and one for ashamed (with triumphant). Surprise is positively correlated with each of the positive emotions, and negatively correlated with all negative emotions except embarrassed, depressed, and disgusted. These results indicate that while a single factor solution based on valence might capture a partial activation pattern, it does not behave well for the commonly valenced interpretations of guilt and surprise, and does not provide sufficient explanatory power to aid in understanding how emotions arise on an individual basis (i.e. people do not experience only positive or only negative emotions in an exclusively valenced manner, but instead happen to experience "mixed" positive and negative emotions simultaneously).

The dimensionality of the 20 items from the emotional survey was analyzed using maximum likelihood factor analysis. The eigenvalues of factor solutions of various size greater than one indicated that it would be worthwhile to re-evaluate the usefulness of emotional state measures beyond the unidimensional scale based on valence. Three criteria were used to determine the number of factors to rotate: the standard model noted in the literature that suggests a unidimensional valenced taxonomy of emotional states, the scree test which plots eigenvalues against factor solutions of various size, and the interpretability of factor solutions of various sizes (especially with respect to recalibrational theory). Based on these criteria, we found that the four factor solution fits our data the best. The four-factor model also has a superior Bayesian Information Criteria (BIC of 553.8 and 500.3 for the trustor and trustee models, respectively) when compared to more complex factor solutions such as, for example, a 
twelve-factor model (BIC of 686.34 and 670.7 for the trustor and trustee models, respectively) that retains all factors with positive eigenvalues. ${ }^{11}$

We examined whether the four factor solution provided by factor analysis gives rise to factors consistent with our theory. ${ }^{12}$ Table 5 reports the correlations produced by orthogonal rotations of the four factor model to facilitate the interpretation of the factor loadings. We find that the first latent factor (F1) corresponds to the theoretically identified sets of emotions activated mainly by the shortsighted negative program, while the second factor (F2) corresponds to the negatie emotions activated by the long-sighted program. The third factor (F3) consists entirely of all positive emotions activated by the short-sighted program. Finally, the forth factor (F4) consists of positive emotions activated by the long-sighted program. Therefore, our factor analysis provides further evidence that emotions are activated jointly as subsets identified by our taxonomy of recalibrational activation and functions. For that reason, we next move on to analyzing subsets of emotions predicted by our theory.

\subsection{Regression Analysis of Subsets of Emotions}

Our model of problem states produced by Trust game interactions and the consequent emotion activations (summarized in Figure 3 and Table 2), based on recalibrational theory, predicts 6 unique subsets of emotions (U1-U6). Each subset is a product of the emotions' shared recalibrational features and their activation by short- and/or long-sighted programs. For example, embarrassed, ashamed and guilty belong to the same subset of emotions U6. Specifically, for the trustor, these emotions are activated by the problem feature described by weight $\mathrm{C}$ (Table 2), and for trustee, these emotions are activated by the problem feature described by weight B. Using seemingly unrelated regressions, we estimate how all subsets of emotions are affected by computationally identified problem features that weights A, B, C and D quantify.

Estimation results are presented in Table 6. Evidently, our theory is well supported by these estimation results. For trustor, all 6 subsets of emotions are significantly affected by all weights (i.e., 7 out of 7 weights are significant at $\mathrm{p}<0.01$ level). Similarly, for trustee, all 6 subsets of emotions are significantly affected by at least one of the weights predicted by the theory (i.e., 9 out of 11 weights are

\footnotetext{
${ }^{11}$ The Bayesian information criterion (BIC) is a criterion for model selection among a finite set of models. It is based, in part, on the likelihood function. When fitting models, it is possible to increase the likelihood by adding parameters. A problem with continually adding more parameters, however, is "overfitting" (see Akaike, 1973) that results in higher error rates and a larger sum of squares (see Forster \& Sober, 1994). The BIC resolves this problem by estimating the degree of overfitting and introducing a penalty term for the number of parameters in the model.

${ }^{12}$ We specifically predict based on our recalibrational theory of emotions, that there should exist latent emotion sets based on hypothesized interpersonal and intrapersonal recalibration functions, positive and negative valences, and service to short-sighted and long-sighted programs.
} 
significant). Depending on the subset of emotions, the estimated model successfully explains between $18 \%$ and $53 \%$ (32\% on average) of the variance for trustor and between $18 \%$ and $60 \%$ (44\% on average) for trustee.

In summary, our estimation results show that emotions act in patterned response to computationally identified problem states produced as a result of interactions in the Trust game. Our model based on a recalibrational theory of emotions predicts the activation of emotions very well.

\section{Discussion}

We consider our mapping of situational predictors of emotions and their orchestrated activations of recalibrational emotions a success: our tests of 20 predicted emotional states (specifically, 6 latent subsets of these) following the Trust game demonstrate that our model is successful at predicting emotion activations and that we are able to explain an average of $32 \%$ of the variation in sampled trustor subsets of emotions, and $44 \%$ of the variation in sampled trustee subsets of emotions. Nevertheless, there remains a fair amount of unexplained variation in how strongly emotional experiences are rated by participants. We consider four potential classes of explanations for this variation: first, that participants either have imperfect access to their emotional states or the fidelity of their reports is compromised; second, that the fine tuning of an individual's emotional responsivity is contingent on state, context, and history dependencies; third, that frequency dependent selection maintains different types of strategists in the population, and some of these strategists simply do not experience certain emotions (e.g. guilt) as do others; and fourth, that as a developmental process, individuals gain experience in identifying antecedents of unwelcomed negative emotions and avoid decisions that will disproportionately contributed to their activation - yet the rate of this maturation (in terms of this emotional control) is not the same for all individuals.

People who are asked to rate single emotions may not be able to accurately describe their emotional states (Ellsworth \& Tong, 2006) if emotion experiences are more often and accurately described with multiple words (Ellsworth \& Smith, 1988; Izard, 1977), or with different words among different people or linguistic traditions. Alternatively, we suggest that recalibrational adaptations do not necessarily require "awareness" of their activations and effects, and therefore we do not expect that participants would necessarily have access to all of their emotional states. Nevertheless, the precedent of previous research successful at relating the activation and impact of self-reported emotions in conjunction with experimental games (Ketelaar and Au, 2003) gave us encouragement in pursuing measures of self-reported emotions following an economic game. 
Another obvious issue is that participants may make biased ${ }^{13}$ or untruthful reports.

Experimental economists are particularly concerned that participants "will not 'tell the truth' unless incentives make truth telling compatible with maximizing utility" (Lopes, 1994, p.218). According to a metareview by Camerer and Hogarth (1999) there is no clear evidence that additional financial incentives would improve the quality of responses in a simple survey task like ours. In fact, it has been noted that for short tasks like our emotions survey that people are known to voluntarily complete without problem (because they have sufficient intrinsic motivation to do so), an attempt at increasing compliance or participation via financial incentives often "backfires" with counterintentional effects (for examples see Gneezy and Rustichini, 2000; Mellstrom and Johannesson, 2008). Nevertheless, wary of the possibility that participants may have been incentivized to use efficiency tactics to complete the survey (such as marking all responses with the same value, which would be an expedient technique for clicking through the survey), we reviewed our data and found not a single apparent case of such untruthful behavior.

A modular view of decision making put forth by Kurzban (2010) proposes factors that can affect the degree to which competing programs interact and produce variation at the individual level. We consider two of these factors: state dependency and history dependency. The outcome that best satisfies needs (from an adaptive perspective) is determined by one's state. One's current and immediate state sets a utility on immediate reward. Consider, for example, how one's state of hunger might have an impact on Trust game decisions: the demand for the cash incentives in our Trust game might be relatively greater for a participant who is very hungry and forgot to bring lunch or dinner money to campus with them (because the payment from game interactions will allow them to conveniently purchase food nearby that will satiate hunger), as opposed to a well-fed student who has plenty of cash on hand. In fact, Wang \& Dvorak (2010) report that participants' blood glucose levels manipulated through controlled caloric intake regulated the rate of future discounting, with better-fed participants discounting the future less. Unfortunately, we are unable to account for individual variation in state dependency.

\footnotetext{
${ }^{13}$ Ekman (1999) shows evidence of culture-specific under-expression of experienced negative emotions, while Kotchemidova (2005) shows evidence of culture-specific over-expression of experienced positive emotions. To ascertain whether subjects biased reporting of positive emotions relative to negative emotions, we examine the constants terms from the fitted seemingly unrelated regressions. Comparing the significant constants for the reported positive emotions to those reported for the negative emotions, we observe higher values for positive than for negative emotions (using Mann-Whitney, $\mathrm{p}<0.01$ for the trustee and $\mathrm{p}<0.02$ for the trustor), which could result from either or both of the noted cultural biases. If this form of bias is homogeneous it should not result in unexplained variance as the models in sections 4.1 and 4.3 allow for a fitted constant for each reported emotion or subset of activated emotions. If, on the other hand, the bias is heterogeneous in our population, our lack of identifying information would prevent us from controlling for the role of culture.
} 
When a decision dilemma is faced, a statistical composite of historical outcomes may be taken into consideration (Heckhausen \& Schulz, 1995). The alternative that has corresponded to the greatest positive emotional activation (goal achievement and reward) in the past, and that has been least associated with negative emotional activation (unachieved goals and unwelcomed consequences), has greater competitive advantage over other competing alternatives. Consider two examples suggested by Baier (1986) and Hardin $(1991,1992)$. The first example is made with "the case of many children of American inner-city communities wrecked by poverty, drugs, and broken families" and the second example concerns women "who have suffered substantial abuse in their early years from the very persons who might have provided the first experience of trustworthiness" (Hardin, 1992, p.161). In both of these examples, groups have been identified whose history dependency puts them at a relative disadvantage when in situations where optimistic trust could lead to gains from exchange (with trustworthy partners) and their social emotions show desensitization when taken advantage of by opportunistic trustees. We are unable to account for individual variation in history dependency.

Frequency dependent selection (Maynard Smith, 1982; Boyd, 1989; Boyd \& Richerson, 1992; Binmore, 1998) can produce relatively stable mixed types of emotion-strategies in a population (e.g. see Lomborg, 1996), a phenomenon which might contribute to individual variation in emotional reports (Ketelaar, 2004; Mealey, 1995) . For example, sociopaths who do not respond to remedial social gestures and likely lack the "moral" emotions that the long-sighted program produces (e.g. see King-Cases, 2008), comprise about 5\% of the adult population (Mealey, 1995). As Mealey (1995, p.124) stated, we suspect that "as long as evolutionary pressures for emotions as reliable communication and commitment devices leading to long-term cooperative strategies coexist with counter pressures for cheating, deceptions, and 'rational' short-term selfishness, a mixture of phenotypes will result, such that some sort of statistical equilibrium will be approached". We are unable to account for individual variation in types that exist in our sample.

Finally, the last possibility which we introduce into this discussion of why we cannot fully explain individual variation in our data on emotional states is that both the tuning of decision strategies ${ }^{14}$ and the sensitivity-tuning of consequential emotions ${ }^{15}$ develops over the lifecourse, as a

\footnotetext{
${ }^{14}$ As individuals age, their abilities become impacted by biological (e.g. muscular strength, motor skills, cognitive ability, susceptibility to illness) and social constraints (e.g. age stratification, expectations about age-based self-control), in turn affecting the consequences of their decisions when faced with dilemmas. All the while, the "secondary control" (via superordinate emotion programs) over one's goal pursuits compensates for biological and social constraints while also reevaluating the tradeoffs between goal pursuits inherent in choice dilemmas based history dependencies. Further complicating the dynamics of self control and decision making across the lifespan is the observation that people have lifestage specific utilities and commitments (i.e. state dependencies) with respect to distinct goal pursuits (McGregor \& Little, 1998).
} 
consequence of experience-based learning (Heckhausen \& Schulz, 1995) that leads to wiser decision making and emotional maturation. Studies of revealed risk preferences and self-control show that future discount rates decrease throughout childhood (3-12 years) (Metcalfe \&Mischel, 1999; Mischel \& Metzner, 1962; Mischel et al., 1989), and continue to decrease into young adulthood (Green et al., 1994; 1996; 1999), plateauing sometime between middle adulthood ( 35+ years; e.g. see Bishai, 2004) and oldest ages (80 years; see Kirby et al, 2002). We presume that older adults in pursuit of long-term goals feel relatively less regret, frustration, or feelings of effort, than would younger adults. Given the large amounts of heterogeneity at specific ages and the dramatic changes that the cited literature has observed in preferences for short-term vs. long-term rewards across the ages represented by an undergraduate study population like ours, we suspect that there exists a fair amount of uncontrolled maturational variation in emotional responsitivity.

\section{Conclusions}

Explanations of how our psychological and behavioral systems function can be distinguished as either proximate (how and when a mechanism does what it does) or ultimate (what the mechanism has been selected to do) (Barkow et al., 1992; Buss, 1995; Dawkins, 1986; Hinde, 1966; Tinbergen, 1963; Mayr, 1988). While we develop theory of emotions' ultimate function and derive our predictions of antecedents from it, we only test the functioning (i.e. the activation) of emotions' proximately. Future studies can take our findings one step further and test for ultimate functions by examining whether the future actions of those individuals who report emotions under the predicted conditions are affected as theory predicts. Three studies which we know of have taken this approach to testing ultimate functions already: Ketelaar \& Au (2003) who demonstrated how the experience of guilt leads to choices of cooperation over opportunism, Fehr \& Gachter (2002) who demonstrated that angry individuals are more likely to engage in costly punishment, and Dunn \& Schweitzer (2005) who have shown that trustor happiness and gratitude increase trust in the Trust game.

It may be that the current literature has explored anger and guilt because they are among the more reliably predictable emotions to result in cooperative game contexts. Following the Trust game,

\footnotetext{
${ }^{15}$ Shaver et al., (1987) reviews literature that provides evidence for how knowledge of (Bretherton \& Beeghly, 1982; Reichenbach \& Masters, 1983; Russell \& Ridgeway, 1983; Masters \& Carlson, 1984) and control over (Masters \& Carlson, 1984: Saarni, 1979, 1984; Johnson, 1983) emotions develops dramatically between birth and adulthood. Studies using emotional primes demonstrate that while older adults are equally capable of experiencing negative emotions (Kunzmann $\&$ Gruhn, 2005), they tend towards behaviors that avoid the priming of negative emotions (Isaacowitz et al., 2006). Socioemotional selectivity theory (Carstensen, 1987; Lang \& Carstensen, 2001) suggests that by later adulthood, adults are relatively more interested in relationships that generate wellbeing and show the benefits of investment (e.g. family relationships, long-term friendships).
} 
anger was the best predicted emotion among our trustors $\left(\mathrm{p}<0.0001, \mathrm{R}^{2}=0.60\right)$ and guilt was one of the best predicted emotions among our trustees $\left(\mathrm{p}<0.0001, \mathrm{R}^{2}=0.55\right)$. For trustees, the emotional states happy, appreciative, and content were predicted as successfully as guilt, suggesting that they might similarly demonstrate recalibrational functions if the effects of their activations were examined in subsequent games.

In light of this theory, we have identified the mechanics that would need to be engineered to produce an emotional equilibrium: a condition in which the emotional impact of people's behavior on each other and on themselves is one in which all engaged programs are kept in the same relative state (before and after action). An important implication of this stable equilibrium is that even under such conditions, the mind is expected to remain conflicted. The important proscription that might be derived from such a consideration is that a steady emotional state might be more closely approached in so far as one is prepared to properly anticipated the experience of both positive and negative emotions; a "conflicted mind" is not a fluke, but a normal predictable condition.

The experience of mixed emotions has received only minimal attention by experimentalists, likely because it is not appreciated as a core trait of human nature. The experience of mixed emotions may not be regarded as a reliable steady state of being because it challenges our intuitions of singular internal interests and the consonance of a non-contradictory self-representation. But what can we make of these conflicted inner-workings? Kurzban (2010, p.56) suggests, "if it's true that your brain consists of many, many little modules with various functions, and if only a small number of them are conscious, then there might not be any particular reason to consider some of them to be "you" or "really you" or your "self"..." And for that matter, there might be no particular reason to consider your intuitions about your choices, or your ability to know your "self" reliably." While the implications of a modular recalibrational theory of emotions might be existentially and even epistemologically difficult to grapple with, we feel this theoretical perspective still provides practical implications for mental health professionals and laypeople alike.

Psychotherapists often treat patients who complain of and suffer from emotional states - and it is not uncommon for patients that patronize these professionals to seek an escape from unwelcomed negative emotions (e.g. see Nesse 1991, 2000). Treatment of these emotions, whether through behavioral intervention or psychopharmaceutical treatment, may benefit from the degree to which psychologists, psychiatrists, and counselors are (1) informed of the functional uniqueness and similarities distinguishing the emotions and their taxonomic classifications, and (2) informed of the choice dilemmas and post-decision situations from which emotional experiences precipitate. Perhaps the most valuable message that our perspective delivers is that it is not necessarily optimal to aspire for 
a pure state of happiness via complete transcendence or removal of "negative" emotional states - in fact it could be harmful. Life entails suffering and happiness, both positive and negative emotional states serve their functions, recalibrating our own inner-workings as well as the inner-workings of those that we interact with. Given the uncertain future, we need to constantly engage in recalibration of ourselves and others to make the most of opportunities given our needs. 


\section{References}

Akaike, H. (1973). Information theory and an extension of the maximum likelihood principle. In: Second International Symposium of Information Theory. B.N. Petrov and F. Csaki (eds.) (pp.267281). Budapest: Akademiai Kiado.

Algoe, S., \& Haidt, J., \& Gable, S. (2008). Beyond reciprocity: Gratitude and relationships in everyday life. Emotion, 8, 425-429.

Algoe, S., Haidt, J., (2009). Witnessing Excellence in Action: The other-praising emotions of elevation, admiration, and gratitude. Journal of Positive Psychology, 4, 105-127.

Averill, J.R. (1975). A semantic atlas of emotional concepts. JSAS: Catalog of Selected Documents in Psychology, 5(421):330.

Baier, Annette (1986), Trust and antitrust. Ethics 96:231-260

Barkow, J.H., Cosmides, L., and Tooby, J. 1992. The Adapted Mind. New York, NY: Oxford University Press.

Barrett, H.C. 2005. Barrett, H. C. (2005). Enzymatic computation and cognitive modularity. Mind and Language, 20:259-287.

Psychological Bulletin, 115(2), 243-267.

Berg, J., Dickhaut, J., and McCabe, K. (1995). Trust, reciprocity, and social history. Games and Economic Behavior, 10:122-142.

Binmore, K. (1998). Game theory and the social contract: Volume 2. Just playing. Cambridge, MA: MIT Press.

Bishai, D.M. (2004). Does time preference change with age? Journal of Population Economics 17(4):583-602

Bowlby, J. (1969). Attachment and loss: Volume l. Attachment. New York: Basic Books.

Boyd, R. (1989). Mistakes allow evolutionary stability in the repeated prisoner's dilemma game. Journal of Theoretical Biology, 136:47-56.

Boyd, R., \& Richardson, P. J. (1992). Punishment allows the evolution of cooperation (or anything else) in sizeable groups. Ethology and Sociobiology, 13:71-195.

Buck, R. (1999). The Biological affects: A typology. Psychological Review, 106:301-336.

Burt, C. (1950). The factorial study of emotions. In M.L. Reymert (ed.) Feelings and emotions. New York: McGraw-Hill.

Butt, A.N., Choi, J.N., \& Jaeger, A.M (2005). The effects of self-emotion, counterpart emotion, and counterpart behavior on negotiator behavior: a comparison of individual level and dyad level dynamics. Journal of Organizational Behavior. 26(6): 681-704

Buss, D.M. (1995). Evolutionary psychology: A new paradigm for psychological science. Psychological Inquiry, 6:1-30

Cacioppo, J.T., Gardner, W.L., and Berntson, G.G. (1999). The affect system has parallel and integrative processing components: Form follows function. Journal of Personality and Social Psychology, 76:839-855.

Carver, C.S. \& Scheier, M.F. 1990. Origins and functions of positive and negative affect: a controlprocess view. Psychological Review 97:19-35

Cattell, R.B. (1946). The Description and Measurement of Personality. New York: Harcourt Brace Jovanovich.

Cosmides, L. and Tooby, J. (2000). Evolutionary psychology and the emotions In M. Lewis \& J. M. Haviland-Jones (Eds.), Handbook of Emotions, 2nd Edition. (pp. 91-115.) NY: Guilford.

Cosmides, L. and Tooby, J. (1989). Evolutionary psychology and the generation of culture, part ii. case study: A computational theory of social exchange. Ethology and Sociobiology, 10(1-3):51-97. 
Costa, P. T. J., \& McCrae, R. R. (1980). Influence of extraversion and neuroticism on subjective wellbeing: Happy and unhappy people. Journal of Personality and Social Psychology, 38: 688-678.

Damasio, A.R. (1994). Descartes Error: Emotion, Reason, and the Human Brain. New York: Frosset/Putnam.

Danner, M., Kasl, S., Abramson, J.L., Vaccarino, V. (2003). Association between depression and elevated c-reactive protein. Psychosomatic Medicine, 65(3):347-356

Darwin, C. (1872). Expression of Emotions in Man and Animals. Chicago: University of Chicago Press. [1965 version]

Dawkins, R. D. (1986). The Blind Watchmaker. Oxford: Oxford University Press.

de Catanzaro, D. (1980). Human suicide: A biological perspective. Behavioral and Brain Sciences, 3:265-90.

de Catanzaro, D. (1991). Evolutionary limits to self-preservation. Ethology and Sociobiology, 12:1328.

de Jong, P.J. (1999). Communicative and remedial effects of social blushing. Journal of Nonverbal Behavior 23(3)197-217

Dunn, J. \& Schweitzer, M. (2005). Feeling and believing: The influence of emotion on trust. Journal of Personality and Social Psychology, 88: 736-748.

Ellsworth, P. C. \& Smith, C. A. (1988)a. From appraisal to emotion: differences among unpleasant feelings. Motivation and Emotion 12, 271-302.

Ellsworth, P. C. \& Smith, C. A. (1988)b. Shades of joy: patterns of appraisal differentiating pleasant emotions. Cognition and Emotion 2, 301-331.

Ellsworth, P.C. \& Tong, M.W. (2006). What does it mean to be angry at yourself? Categories, appraisals, and the problem of language. Emotion 6(4):572-586

Elster, J. (1995). Rationality and the emotions. The Economic Journal. 116:1386-1397.

Fehr, E. \& Gächter, S. (2002). Altruistic punishment in humans. Nature 415:137-40.

Fischbacher, U. (2007). z-Tree: Zurich toolbox for ready-made economic experiments. Experimental Economics, 10(2): 171-178.

Frank, R.L. (1988). Passions Within Reason: the Strategic Role of the Emotions. NY: Norton.

Gneezy, U. and Rustichini, A. (2000a). A fine is a price. The Journal of Legal Studies, 29(1):1 17.

Gray, J.A. (1971). The Psychology of Fear and Stress. New York: McGraw-Hill

Green, L., Myerson, J., \& Ostaszewski, P. (1999). Discounting of delayed rewards across the life span: age differences in individual discounting functions. Behavioural Processes, 46(1), 89-96.

Green, L., Myerson, J., Lichtman, D., Rosen, S., \& Fry, A. (1996). Temporal discounting in choice between delayed rewards: the role of age and income. Psychology and Aging, 11(1), 79-8

Grinde, B. (2002). Happiness in the perspective of evolutionary psychology. Journal of Happiness Studies 3: 331-354

Guilford, J.P. \& Zimmerman, W.S. (1956). Fourteen dimensions of temperament. Psychological Monograph 70(417):10.

Haidt, J. (2003a). The moral emotions. In R. J. Davidson, K. R. Scherer, \& H. H. Goldsmith (Eds.), Handbook of affective sciences. Oxford: Oxford University Press.(pp. 852-870).

Haidt, J. (2003b). Elevation and the positive psychology of morality. In C. L. M. Keyes \& J. Haidt (Eds.) Flourishing: Positive psychology and the life well-lived. Washington DC: American Psychological Association. (pp. 275-289).

Hardin, R. (1991). Trusting persons, trusting institutions, in Richard Zeckhauser (ed.) The Strategy of Choice, (pp. 185-209), Cambridge, MA: MIT Press.

Hardin, R. (1992). The street-level epistemology of trust. Analyse \& Kritik 14:S.152-176.

Haselton, M.G. \& Ketelaar, T. (2006). Irrational emotions or emotional wisdom? The evolutionary psychology of emotions and behavior. In J. P. Forgas (Ed.), Hearts and minds: Hearts and minds: Affective influences on social cognition and behavior (pp. 21-40). New York: Psychology Press 
Heckhausen, J. \& Schulz, R. (1995). A Life-span theory of control. Psychological Review. 102(2): 284-30

Hernstein, R. (1970). On the law of effect. Journal of Experimental Analysis of Behavior, 13: 242-266.

Hill, K., R. S. Walker, M. Bozicevic, J. Eder, T. Headland, B. Hewlett, A. M. Hurtado, F. Marlowe, P. Wiessner, and B. Wood. (2011). Co-residence patterns in hunter-gatherer societies show unique human social structure. Science 331:1286-1289

Hinde, R. A. (1970). Animal Behaviour: A Synthesis of Ethology and Comparative Psychology. New York:: McGraw-Hill.

Hirschleifer, J. (1987). On the emotions as guarantors of threats and promises. in J. Dupre, (ed.) The Latest On the Best: Essays on Evolution and Optimality (pp.307-326). Boston: MIT Press.

Izard, C.E. (1977). Human Emotions. New York: Plenum

James, W. (1890). The Principles of Psychology, Vol. 2. Chapter 25: The Emotions. NY: Henry Holt \& Co.

Johnson, D., Stopka, P., Knights, S., (2003). The puzzle of human cooperation. Nature 421, 911-912.

Kaiser, H.F. (1974). An index of factorial simplicity. Psychometrika 39 (1) , 31-36.

Kaplan, H., Hill, K., Cadelina, R., Hayden, B., Hyndman, D., Preston, R., Smith, E., Stuart, D., and Yesner, D. (1985). Food sharing among ache foragers: Tests of explanatory hypotheses. Current Anthropology, 26(2):223-246.

Keltner D, Buswell BN (1997): Embarrassment: Its distinct form and appeasement functions. Psychological Bulletin. 122(3):250-270

Keltner, D., Young, R.C., \& Buswell, B.N. (1997). Appeasement in human emotion, social practice, and personality. Aggressive Behavior 23:359-374.

Ketelaar, T. \& Au, W. T. (2003). The effects of guilty feelings on the behavior of uncooperative individuals in repeated social bargaining games: An Affect-as-information interpretation of the role of emotion in social interaction. Cognition \& Emotion, 17, 429-453

Ketelaar, T. (2004). Ancestral Emotions, Current Decisions: Using Evolutionary Game Theory to explore the role of Emotions in decision-making. Crawford, C. \& Salmon, C. (Eds). Darwinism, Public Policy and Private Decisions, (pp145-168). Lawrence Erlbaum Associates.

Ketelaar, T. (2006). The role of moral sentiments in economic decision making. In DeCremer, D., Zeelenberg, M., \& Murnighan, K. (Eds.) Social Psychology and Economics. Lawrence Erlbaum Associates, pp. 97-116.

King-Cases, B., Sharp, C., Lomax-Bream, L., Lohrenz, T., Fonagy, P., \& Montague, P.R. (2008). The rupture and repair of cooperation in borderline personality disorder. Science, 321:806-810

Kirby, K.N., Godoy, R., Reyes-Garcia, V., Byron, E., Apaza, L., Leonard, W., Perez, E., Vadez, V., \& Wilkie, D. (2002). Correlates of delay-discount rates: evidence from Tsimane' amerindians of the Bolivian rain forest. Journal of Economic Psychology 23:291-316.

Kotchemidova, C. (2005). From good cheer to "drive-by smiling": a social history of cheerfulness. Journal of Social History, 39(1):5-37

Kurzban, R. (2010). Why Everyone (Else) Is a Hypocrite: Evolution and the Modular Mind. Princeton, NJ: Princeton University Press.

Larmer, B. (2008). "Bhutan's Enlightened Experiment". National Geographic. ISSN 0027-9358. Retrieved 2011-08-24 @ http://ngm.nationalgeographic.com/2008/03/bhutan/larmer-text

Larsen, J.T., McGraw, A.P., Cacciopo, J.T. (2001). Can people feel happy and sad at the same time? Journal of Personality and Social Psychology 81:684-696

Larsen, J.T., McGraw, A.P., Mellers, B.A., and Cacioppo, J.T. (2004). The agony of victory and thrill of defeat. Psychological Science 15(5):325-330

Lerner, J. S. \& Keltner, D. (2000). Beyond valence: Toward a model of emotion-specific influences on judgment and choice. Cognition and Emotion, 14, 473-493. 
Lerner, J. S. \& Keltner, D. (2001). Fear, anger, and risk. Journal of Personality and Social Psychology, 81, 146-159.

Levenson, R.W. (1994). Human emotion: A functional view. In P. Ekman \& R.J. Davidson (Eds.), The

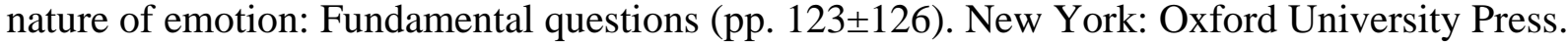

Levenson, R.W. (1999). The Intrapersonal functions of emotion. Cognition and Emotion. 13(5):481504.

Lewis, H.B. (1990). Thinking and feeling - the elephant's tail. In C.A. Maher, M Schwebel, \& N.S. Fagley (eds.), Thinking and Problem-solving in the Developmental Process: International Perspectives (the WORK) (pp.89-110). Hillsdale, NJ: Erlbaum.

Loewenstein, G. (1987). Anticipation and the valuation of delayed consumption. Economic Journal. 97(387): 666-68

Lopes, L.L. (1994). Psychology and economics: perspective on risk, cooperation, the marketplace. Annual Review of Psychology, 45:197-227.

Lutz, C. (1982). The domain of emotion words on Ifaluk. American Ethnologist, 9, 113-128.

Maynard Smith, J. (1982). Evolution and the Theory of Games. Cambridge: Cambridge University Press.

Mayr, E. (1988). Towards a New Philosophy of Biology. Cambridge: Belknap Press of the Harvard University Press.

McCullough, M. E., Kilpatrick, S. D., Emmons, R. A., \& Larson, D. B. (2001). Is gratitude a moral affect? Psychological Bulletin, 127, 249-266.

Mealey, L. (1995). The sociobiology of sociopathy: An integrated evolutionary model. Behavioral and Brain Sciences, 18, 523-599.

Mellers, B.A., and McGraw, A.P. (2001). Anticipated emotions as guides to choice. Current Directions in Psychological Science 10:210-214.

Mellers, B.A., Erev, R.I., Fessler, D.M.T., Hemelrijk, C.K., Hertwig, R., Laland, K.N., Scherer, K.R., Seeley, T.D., Selten, R., and Tetlock, P.E. (2001). Group report: Effects of emotions and social processes on bounded rationality. in Bounded Rationality: the Adaptive Toolbox, G. Gigerenzer and R. Selten (eds.) Cambridge MA: MIT Press

Mellstrom, C. and Johannesson, M. (2008). Crowding out in blood donation: was Titmuss right? Journal of the European Economic Association, 6(4):845-863.

Metcalfe, J., \& Mischel, W. (1999). A hot/cool-system analysis of delay of gratification: dynamics of willpower. Psychological Review, 106(1), 3-19.

Mischel, W., \& Metzner, R. (1962). Preference for delayed reward as a function of age, intelligence, and length of delay interval. Journal of Abnormal of Social Psychology, 64:425-431.

Mischel, W., Shoda, Y., \& Rodriguez, M. L. (1989). Delay of gratification in children. Science, 244(4907):933-938.

Nesse, R.M. (1990). Evolutionary explanations of emotions. Human Nature 1(3):261-289.

Nesse, R.M. (1991). What good is feeling bad? The evolutionary benefits of psychic pain. The Sciences November/December:30-37

Nesse, R.M. (2000). Is Depression an Adaptation? Archives of General Psychiatry 57:14-20.

Nesse, R.M. (2004). Natural selection and the elusiveness of happiness. Philosophical Transactions of the Royal Society of London B. 359:1333-1347.

Ortony, A., \& Turner, T. J. (1990). What's basic about basic emotions? Psychological Review, 97, $315-331$.

Ortony, A., Clore, G. L. \& Collins, A. (1988) The Cognitive Structure of Emotions. Cambridge, NY: Cambridge University Press.

Osgood, C. E., May, W. H., \& Miron, M. S. (1975). Cross-cultural Universals of Affective Meaning. Urbana: University of Illinois Press. 
Plutchik, R. \& Kellerman, H. (eds.) (1980). Theories of Emotion. Emotion: Theory, Research, and Experience. Vol. 1, New York: Academic Press.

Plutchik, R. (1980). Emotion: A Psychoevolutionary Synthesis. New York: Harper \& Row.

Rand, Ayn (1964). The Virtue of Selfishness. New York: New American Library.

Revkin, A. C. (2005). A New Measure of Well-Being From a Happy Little Kingdom. New York Times, October 4, 2005.

Rozin, P., Haidt, J., \& McCauley, C. R. (1993). Disgust. In M. Lewis \& J. Haviland (Eds.), Handbook of emotions (pp. 575-594). New York: Guilford Press.

Russell, J. A. (1983). Pancultural aspects of the human conceptual organization of emotions. Journal of Personality and Social Psychology, 45, 1281-1288.

Scherer, K.R. (1984). On the nature and function of emotion: A component process approach. in K.R. Scherer and P. Ekman (eds.) Approached to Emotion. Hillsdale, NJ: Lawrence Erlbaum.

Simon, H.A. (1987). Bounded rationality. In: The New Palgrave. A Dictionary of Economics. J. Eatwell et al., (eds) (pp.266-268). London: Macmillan.

Smith, A. (1759). The Theory of Moral Sentiments. 2000 edition. NY: Prometheus Books.

Tellegen, A., Watson, D., Clark, L.A. (1999). On the dimensional and hierarchical structure of affect. Psychological Science, 10, 297-303.

Tinbergen, Niko (1963). "On Aims and Methods in Ethology," Zeitschrift für Tierpsychologie, 20: 410-433

Todd, P.M. (2001). Fast and frugal heuristics for environmentally bounded minds. in Bounded Rationality: the Adaptive Toolbox, G. Gigerenzer and R. Selten (eds.) Cambridge MA: MIT Press

Tooby, J. \& Cosmides, L. (1990). The past explains the present: Emotional adaptations and the structure of ancestral environments. Ethology and Sociobiology, 11, 375-424.

Tooby, J., Cosmides, L., Sell, A., Lieberman, D., and Sznycer, D. (2008). Handbook of Approach and Avoidance Motivation, chapter Internal Regulatory Variables and the Design of Human Motivation: A Computational and Evolutionary Approach, pages 251-271. Mahwah, NJ: Lawrence Erlbaum Associates.

Trivers, R. L. (1971). The evolution of reciprocal altruism. Quarterly Review of Biology, 46(1):35-57.

Van Kleef, G. A., de Dreu, C. W. W., \& Manstead, A. S. R. (2004). The interpersonal effects of emotion in negotiations: A motivated information processing approach. Journal of Personality and Social Psychology, 87, 510-528.

von Neumann, J and Morgenstern, O. (1944). The Theory of Games and Economic Behavior. Princeton, N.J.: Princeton, University Press.

Wang, X.T. and Dvorak, R. D. (2010). Sweet future: Fluctuating blood glucose levels affect future discounting. Psychological Science. 21, 183-188.

Watson, D., Wiese, D., Vaidya, J., \& Tellegen, A. (1999). The two general activation systems of affect: structural findings, evolutionary considerations, and psychobiological evidence. Journal of Personality and Social Psychology, 76:820-838.

Zeelenberg, M. (1999). Anticipated regret, expected feedback and behavioral decision-making. Journal of Behavioral Decision Making, 12:93-106.

Zeelenberg, M., \& Beattie, J. (1997). Consequences of regret aversion 2: Additional evidence for effects of feedback on decision making. Organizational Behavior and Human Decision Processes, $71,1-1$

Zeelenberg, M., Nelissen, R.M.A., Breugelmans, S.M., \& Pieters, R. (2008). On emotion specificity in decision making: Why feeling is for doing. Judgment and Decision Making 3(1):18-27

Zeelenberg, M., Van Dijk, W. W., Van der Pligt, J., Manstead, A. S. R., Van Empelen, P., \& Reinderman, D. (1998). Emotional reactions to the outcomes of decisions: The role of counterfactual thought in the experience of regret and disappointment. Organizational Behavior and Human Decision Processes, 75, 117-141. 
Table 1a. Specific Classifying Features of Emotions.

\begin{tabular}{|c|c|c|c|c|c|c|}
\hline Emotion & $\mathrm{L}$ & $S$ & Pos & $\mathrm{Neg}$ & Intra & Inter \\
\hline Appreciative & $X$ & $X$ & $\mathrm{X}$ & & & X \\
\hline Нарру & $\mathrm{X}$ & $\mathrm{X}$ & $\mathrm{X}$ & & X & $\mathrm{X}$ \\
\hline Content & $X$ & $\mathrm{X}$ & $X$ & & $X$ & $X$ \\
\hline Cheerful & $X$ & X & $\mathrm{X}$ & & $X$ & $X$ \\
\hline Triumphant & $\mathrm{X}$ & $\mathrm{X}$ & $\bar{X}$ & & X & \\
\hline Inspired & X & $X$ & X & & X & \\
\hline Secure & $X$ & $\mathrm{X}$ & $\mathrm{X}$ & & $\mathrm{X}$ & \\
\hline Proud & $X$ & & $\mathrm{X}$ & & $\mathrm{X}$ & \\
\hline Believable & $\mathrm{X}$ & & $\mathrm{X}$ & & $X$ & \\
\hline Surprised & $X$ & $X$ & $\mathrm{X}$ & $X$ & $\mathrm{X}$ & \\
\hline Disgusted & $\mathrm{X}$ & $\mathrm{X}$ & & $\mathrm{X}$ & $\mathrm{X}$ & $\mathrm{X}$ \\
\hline Jealous & $\mathrm{X}$ & $X$ & & $X$ & $\mathrm{X}$ & $\mathrm{X}$ \\
\hline Aggravated & X & X & & $X$ & $\mathrm{X}$ & $\mathrm{X}$ \\
\hline Frustrated & $X$ & $\mathrm{X}$ & & $\mathrm{X}$ & $\mathrm{X}$ & $\mathrm{X}$ \\
\hline Angry & $\mathrm{X}$ & $\mathrm{X}$ & & $\mathrm{X}$ & $\mathrm{X}$ & $\mathrm{X}$ \\
\hline Depressed & X & X & & $X$ & $X$ & $X$ \\
\hline Sad & $X$ & $\mathrm{X}$ & & X & $\mathrm{X}$ & $\mathrm{X}$ \\
\hline Embarrassed & $\mathrm{X}$ & & & $\mathrm{X}$ & $X$ & $X$ \\
\hline Ashamed & $\mathrm{X}$ & & & $\mathrm{X}$ & $\bar{X}$ & $\bar{X}$ \\
\hline Guilty & X & & & $X$ & $X$ & \\
\hline
\end{tabular}

Table 1a. The twenty emotions included in our modified PANAS are defined according to their recalibrational functions; specifically, whether they (1) are employed by short-sighted and/or long-sighted program(s) for recalibration, (2) create a positive and/or negative affect valence (maintaining calibrations when successful or downregulating competing programs that caused activating program's failure, respectively), and (3) directly or indirectly target self and/or other with recalibrational efforts (therefore qualifying as intra-personal and/or interpersonal). 
Table 1b. Weighted Activation of Trustors' Emotions, Type of Recalibration by Emotion, and Program Targeted Recalibration.

\begin{tabular}{|c|c|c|c|c|c|c|c|c|c|c|c|c|c|c|c|c|}
\hline \multirow[b]{3}{*}{ Emotion } & \multicolumn{4}{|c|}{ "A" Weight } & \multicolumn{4}{|c|}{ "B" Weight } & \multicolumn{4}{|c|}{ "C" Weight } & \multicolumn{4}{|c|}{ “D” Weight } \\
\hline & \multicolumn{2}{|c|}{ Long-sighted } & \multicolumn{2}{|c|}{ Short-sighted } & \multicolumn{2}{|c|}{ Long-sighted } & \multicolumn{2}{|c|}{ Short-sighted } & \multicolumn{2}{|c|}{ Long-sighted } & \multicolumn{2}{|c|}{ Short-sighted } & \multicolumn{2}{|c|}{ Long-sighted } & \multicolumn{2}{|c|}{ Short-sighted } \\
\hline & Inter & Intra & Inter & Intra & Inter & Intra & Inter & Intra & Inter & Intra & Inter & Intra & Inter & Intra & Inter & Intra \\
\hline Appreciative & $(+\mathrm{L})$ & & $(+\mathrm{L})$ & & & & & & & & & & & & & \\
\hline Happy & $(+\mathrm{L})$ & $(+\mathrm{L})$ & $(+\mathrm{L})$ & $(+\mathrm{L})$ & & & & & & & & $(+\mathrm{S})$ & & & & \\
\hline Content & $(+\mathrm{L})$ & $(+\mathrm{L})$ & $(+\mathrm{L})$ & $(+\mathrm{L})$ & & & & & & & & $(+S)$ & & & & \\
\hline Cheerful & $(+\mathrm{L})$ & $(+\mathrm{L})$ & $(+\mathrm{L})$ & $(+\mathrm{L})$ & & & & & & & & $(+\mathrm{S})$ & & & & \\
\hline Triumphant & & $(+\mathrm{L})$ & & $(+\mathrm{L})$ & & & & & & & & $(+\mathrm{S})$ & & & & \\
\hline Inspired & & $(+\mathrm{L})$ & & $(+\mathrm{L})$ & & & & & & & & $(+S)$ & & & & \\
\hline Secure & & $(+\mathrm{L})$ & & $(+\mathrm{L})$ & & & & & & & & $(+S)$ & & & & \\
\hline Proud & & $(+\mathrm{L})$ & & & & & & & & & & & & & & \\
\hline Believable & & & & & & & & & & & & & & & & \\
\hline Surprised & & & & & & & & & & & & & & $(-\mathrm{L})$ & & $(-S)$ \\
\hline Disgusted & & & & & $(-S)$ & & $(-S)$ & $(-\mathrm{L})$ & & & & & & & & \\
\hline Jealous & & & & & $(-S)$ & & $(-S)$ & $(-\mathrm{L})$ & & & & & & & & \\
\hline Aggravated & & & & & $(-S)$ & & $(-S)$ & $(-\mathrm{L})$ & & & & & & & & \\
\hline Frustrated & & & & & $(-S)$ & & $(-S)$ & $(-\mathrm{L})$ & & & & & & & & \\
\hline Angry & & & & & $(-S)$ & & $(-S)$ & $(-\mathrm{L})$ & & & & & & & & \\
\hline Depressed & & & & & $(-S)$ & & $(-S)$ & $(-\mathrm{L})$ & & & & & & & & \\
\hline Sad & & & & & $(-S)$ & & $(-S)$ & $(-\mathrm{L})$ & & & & & & & & \\
\hline Embarrassed & & & & & & & & & $(-\mathrm{L})$ & $(-S)$ & & & & & & \\
\hline Ashamed & & & & & & & & & $(-\mathrm{L})$ & $(-S)$ & & & & & & \\
\hline Guilty & & & & & & & & & & $(-S)$ & & & & & & \\
\hline
\end{tabular}

"+" = recalibration by upregulation, "_"=recalibration by downregulation; $\mathrm{L}=$ long-sighted program targeted, $\mathrm{S}=$ short-sighted program targeted 
Table 1c. Weighted Activation of Trustees' Emotions, Type of Recalibration by Emotion, and Program Targeted Recalibration.

\begin{tabular}{|c|c|c|c|c|c|c|c|c|c|c|c|c|c|c|c|c|}
\hline \multirow[b]{3}{*}{ Emotion } & \multicolumn{4}{|c|}{ "A" Weight } & \multicolumn{4}{|c|}{ "B" Weight } & \multicolumn{4}{|c|}{ “C" Weight } & \multicolumn{4}{|c|}{ “D” Weight } \\
\hline & \multicolumn{2}{|c|}{ Long-sighted } & \multicolumn{2}{|c|}{ Short-sighted } & \multicolumn{2}{|c|}{ Long-sighted } & \multicolumn{2}{|c|}{ Short-sighted } & \multicolumn{2}{|c|}{ Long-sighted } & \multicolumn{2}{|c|}{ Short-sighted } & \multicolumn{2}{|c|}{ Long-sighted } & \multicolumn{2}{|c|}{ Short-sighted } \\
\hline & Inter & Intra & Inter & Intra & Inter & Intra & Inter & Intra & Inter & Intra & Inter & Intra & Inter & Intra & Inter & Intra \\
\hline Appreciative & $(+\mathrm{L})$ & & & & & & & & & & & & & & $(+\mathrm{L})$ & \\
\hline Happy & $(+\mathrm{L})$ & $(+\mathrm{L})$ & & & & & & & & & & & & & $(+\mathrm{L})$ & $(+\mathrm{S})$ \\
\hline Content & $(+\mathrm{L})$ & $(+\mathrm{L})$ & & & & & & & & & & & & & $(+\mathrm{L})$ & $(+S)$ \\
\hline Cheerful & $(+\mathrm{L})$ & $(+\mathrm{L})$ & & & & & & & & & & & & & $(+\mathrm{L})$ & $(+\mathrm{S})$ \\
\hline Triumphant & & $(+\mathrm{L})$ & & & & & & & & & & & & & & $(+\mathrm{S})$ \\
\hline Inspired & & $(+\mathrm{L})$ & & & & & & & & & & & & & & $(+\mathrm{S})$ \\
\hline Secure & & $(+\mathrm{L})$ & & & & & & & & & & & & & & $(+S)$ \\
\hline Proud & & $(+\mathrm{L})$ & & & & & & & & & & & & & & \\
\hline Believable & & $(+\mathrm{L})$ & & & & & & & & & & & & & & \\
\hline Surprised & & $(+\mathrm{L})$ & & & & & & & & $(-\mathrm{L})$ & & $(-\mathrm{S})$ & & & & $(+\mathrm{S})$ \\
\hline Disgusted & & & & $(-\mathrm{L})$ & & & & & $(-S)$ & & $(-S)$ & & & & & \\
\hline Jealous & & & & $(-\mathrm{L})$ & & & & & $(-S)$ & & $(-S)$ & & & & & \\
\hline Aggravated & & & & $(-\mathrm{L})$ & & & & & $(-S)$ & & $(-S)$ & & & & & \\
\hline Frustrated & & & & $(-\mathrm{L})$ & & & & & $(-\mathrm{S})$ & & $(-\mathrm{S})$ & & & & & \\
\hline Angry & & & & $(-\mathrm{L})$ & & & & & $(-S)$ & & $(-S)$ & & & & & \\
\hline Depressed & & & & $(-\mathrm{L})$ & & & & & $(-S)$ & & $(-S)$ & & & & & \\
\hline Sad & & & & $(-\mathrm{L})$ & & & & & $(-S)$ & & $(-S)$ & & & & & \\
\hline Embarrassed & & & & & $(-\mathrm{L})$ & $(-S)$ & & & & & & & & & & \\
\hline Ashamed & & & & & $(-\mathrm{L})$ & $(-S)$ & & & & & & & & & & \\
\hline Guilty & & & & & & $(-S)$ & & & & & & & & & & \\
\hline
\end{tabular}

"+" = recalibration by upregulation, "-"=recalibration by downregulation; L = long-sighted program targeted, $\mathrm{S}=$ short-sighted program targeted 
Table 2. Predicted Emotional Activations Based on Trust Game Outcome Weights.

\begin{tabular}{|c|c|c|c|}
\multirow{2}{*}{ Emotion } & \multirow{2}{*}{ Subset } & \multicolumn{3}{|c|}{ Activation of Emotion for } \\
\cline { 3 - 4 } & Trustor & Trustee \\
\hline Appreciative & U1 & A & A, D \\
\hline Happy & U2 & A, C & A, D \\
\hline Content & U2 & A, C & A, D \\
\hline Cheerful & U2 & A, C & A, D \\
\hline Triumphant & U2 & A, C & A, D \\
\hline Inspired & U2 & A, C & A, D \\
\hline Secure & U2 & A, C & A, D \\
\hline Proud & U3 & A & A \\
\hline Believable & U3 & $\varnothing$ & A \\
\hline Surprised & U4 & D & A, C, D \\
\hline Disgusted & U5 & B & A, C \\
\hline Jealous & U5 & B & A, C \\
\hline Aggravated & U5 & B & A, C \\
\hline Frustrated & U5 & B & A, C \\
\hline Angry & U5 & B & A, C \\
\hline Depressed & U5 & B & A, C \\
\hline Sad & U5 & B & A, C \\
\hline Embarrassed & U6 & C & B \\
\hline Ashamed & U6 & C & B \\
\hline Guilty & U6 & C & B \\
\hline & & & \\
\hline
\end{tabular}


Table 3. Individual Emotional Activations Based on Trust Game Outcome Weights.

\begin{tabular}{|c|c|c|c|c|c|c|c|c|c|c|}
\hline \multirow[b]{3}{*}{ Emotion } & \multicolumn{5}{|c|}{ Trustor } & \multicolumn{5}{|c|}{ Trustee } \\
\hline & \multicolumn{4}{|c|}{ Independent Variables } & \multirow[b]{2}{*}{ R-sq } & \multicolumn{4}{|c|}{ Independent Variables } & \multirow[b]{2}{*}{$\mathrm{R}$-sq } \\
\hline & A & B & $\mathrm{C}$ & $\mathrm{D}$ & & A & $\mathrm{B}$ & $\mathrm{C}$ & $\mathrm{D}$ & \\
\hline Appreciative & $\begin{array}{c}0.49 * * * \\
(0.10)\end{array}$ & & & & 0.325 & $\begin{array}{c}0.31 * * * \\
(0.10)\end{array}$ & & & $\begin{array}{c}0.38 * * * \\
(0.09)\end{array}$ & 0.521 \\
\hline Happy & $\begin{array}{c}0.56^{* * * *} \\
(0.13)\end{array}$ & & $\begin{array}{l}0.12 * \\
(0.07)\end{array}$ & & 0.356 & $\begin{array}{l}0.22 * * \\
(0.08)\end{array}$ & & & $\begin{array}{c}0.37 * * * \\
(0.07)\end{array}$ & 0.538 \\
\hline Content & $\begin{array}{c}0.55^{* * * *} \\
(0.13)\end{array}$ & & $\begin{array}{l}0.18^{* * *} \\
(0.07)\end{array}$ & & 0.286 & $\begin{array}{c}0.28 * * * \\
(0.08)\end{array}$ & & & $\begin{array}{c}0.34 * * * \\
(0.07)\end{array}$ & 0.577 \\
\hline Cheerful & $\begin{array}{c}0.55^{* * * *} \\
(0.14) \\
\end{array}$ & & $\begin{array}{l}0.13^{*} \\
(0.07) \\
\end{array}$ & & 0.308 & $\begin{array}{c}0.24 * * * \\
(0.08) \\
\end{array}$ & & & $\begin{array}{c}0.33^{* * *} \\
(0.07) \\
\end{array}$ & 0.513 \\
\hline Triumphant & $\begin{array}{l}0.34 * * \\
(0.13)\end{array}$ & & $\begin{array}{c}0.05 \\
(0.07)\end{array}$ & & 0.177 & $\begin{array}{l}0.21 * * \\
(0.08)\end{array}$ & & & $\begin{array}{c}0.35^{* * * *} \\
(0.07)\end{array}$ & 0.486 \\
\hline Inspired & $\begin{array}{c}0.45^{* * * *} \\
(0.11)\end{array}$ & & $\begin{array}{c}0.00 \\
(0.06)\end{array}$ & & 0.479 & $\begin{array}{c}0.39 * * * \\
(0.08)\end{array}$ & & & $\begin{array}{c}0.11 \\
(0.08)\end{array}$ & 0.442 \\
\hline Secure & $\begin{array}{c}0.61 * * * \\
(0.13)\end{array}$ & & $\begin{array}{c}0.28 * * * \\
(0.07)\end{array}$ & & 0.340 & $\begin{array}{c}0.25^{* *} \\
(0.10)\end{array}$ & & & $\begin{array}{c}0.25^{* * * *} \\
(0.09)\end{array}$ & 0.323 \\
\hline Proud & $\begin{array}{c}0.29 * * * \\
(0.10)\end{array}$ & & & & 0.178 & $\begin{array}{c}0.59 * * * \\
(0.09)\end{array}$ & & & & 0.523 \\
\hline Believable & & & & & & $\begin{array}{c}0.26 * * \\
(0.10)\end{array}$ & & & & 0.126 \\
\hline Surprised & & & & $\begin{array}{c}0.26 * * * \\
(0.08)\end{array}$ & 0.188 & $\begin{array}{c}0.37 \\
(0.29)\end{array}$ & & $\begin{array}{c}0.02 \\
(0.31)\end{array}$ & $\begin{array}{l}-0.08 \\
(0.38)\end{array}$ & 0.197 \\
\hline Disgusted & & $\begin{array}{c}0.36 * * * \\
(0.07)\end{array}$ & & & 0.376 & $\begin{array}{c}0.01 \\
(0.13)\end{array}$ & & $\begin{array}{c}0.20 * * * \\
(0.07)\end{array}$ & & 0.311 \\
\hline Jealous & & $\begin{array}{c}0.28 * * * \\
(0.07)\end{array}$ & & & 0.292 & $\begin{array}{l}0.19^{*} \\
(0.11)\end{array}$ & & $\begin{array}{c}0.22 * * * \\
(0.06)\end{array}$ & & 0.280 \\
\hline Aggravated & & $\begin{array}{c}0.40 * * * \\
(0.07)\end{array}$ & & & 0.433 & $\begin{array}{c}0.14 \\
(0.11)\end{array}$ & & $\begin{array}{c}0.27 * * * \\
(0.06)\end{array}$ & & 0.439 \\
\hline Frustrated & & $\begin{array}{c}0.45^{* * *} \\
(0.07)\end{array}$ & & & 0.450 & $\begin{array}{c}0.12 \\
(0.12) \\
\end{array}$ & & $\begin{array}{c}0.30^{* * * *} \\
(0.07)\end{array}$ & & 0.446 \\
\hline Angry & & $\begin{array}{c}0.44 * * * \\
(0.05)\end{array}$ & & & 0.603 & $\begin{array}{c}0.06 \\
(0.12) \\
\end{array}$ & & $\begin{array}{c}0.26 * * * \\
(0.06)\end{array}$ & & 0.401 \\
\hline Depressed & & $\begin{array}{c}0.28 * * * \\
(0.06)\end{array}$ & & & 0.295 & $\begin{array}{c}0.08 \\
(0.11)\end{array}$ & & $\begin{array}{c}0.18^{* * * *} \\
(0.06)\end{array}$ & & 0.236 \\
\hline Sad & & $\begin{array}{c}0.14 * * \\
(0.06)\end{array}$ & & & 0.088 & $\begin{array}{l}-0.01 \\
(0.11)\end{array}$ & & $\begin{array}{l}0.13 * * \\
(0.06)\end{array}$ & & 0.197 \\
\hline Embarrassed & & & $\begin{array}{l}0.11 * * \\
(0.05)\end{array}$ & & 0.076 & & $\begin{array}{l}0.19 * * \\
(0.08)\end{array}$ & & & 0.116 \\
\hline Ashamed & & & $\begin{array}{c}0.08 * * \\
(0.04)\end{array}$ & & 0.091 & & $\begin{array}{c}0.33 * * * \\
(0.06)\end{array}$ & & & 0.428 \\
\hline Guilty & & & $\begin{array}{c}0.17 * * * \\
(0.04)\end{array}$ & & 0.272 & & $\begin{array}{c}0.44 * * * \\
(0.06)\end{array}$ & & & 0.545 \\
\hline
\end{tabular}

Note: * indicates statistical significance at $p<0.10,{ }^{* *}$ significant at $p<0.05$, and ${ }^{* * *}$ at $p<0.01$

Standard errors are in parentheses. 
Table 4. Joint Emotional Activations Based on Trust Game Outcome Weights.

\begin{tabular}{|c|c|c|c|c|c|c|c|c|c|c|}
\hline \multirow[b]{3}{*}{ Emotion } & \multicolumn{5}{|c|}{ Trustor } & \multicolumn{5}{|c|}{ Trustee } \\
\hline & \multicolumn{4}{|c|}{ Independent Variables } & \multirow[b]{2}{*}{ R-sq } & \multicolumn{4}{|c|}{ Independent Variables } & \multirow[b]{2}{*}{ R-sq } \\
\hline & $\mathrm{A}$ & B & $\mathrm{C}$ & $\mathrm{D}$ & & $\mathrm{A}$ & $\mathrm{B}$ & $\mathrm{C}$ & $\mathrm{D}$ & \\
\hline Appreciative & $\begin{array}{c}0.40^{* * *} \\
(0.08)\end{array}$ & & & & 0.325 & $\begin{array}{c}0.34 * * * \\
(0.09)\end{array}$ & & & $\begin{array}{c}0.29 * * * \\
(0.07)\end{array}$ & 0.521 \\
\hline Happy & $\begin{array}{c}0.59 * * * \\
(0.09)\end{array}$ & & $\begin{array}{c}0.17 * * * \\
(0.04)\end{array}$ & & 0.356 & $\begin{array}{c}0.22 * * * \\
(0.08)\end{array}$ & & & $\begin{array}{c}0.34 * * * \\
(0.06)\end{array}$ & 0.538 \\
\hline Content & $\begin{array}{c}0.48^{* * * *} \\
(0.10)\end{array}$ & & $\begin{array}{c}0.18^{* * * *} \\
(0.05)\end{array}$ & & 0.286 & $\begin{array}{c}0.29 * * * \\
(0.07)\end{array}$ & & & $\begin{array}{c}0.31 * * * \\
(0.06)\end{array}$ & 0.577 \\
\hline Cheerful & $\begin{array}{c}0.59^{* * * *} \\
(0.10)\end{array}$ & & $\begin{array}{c}0.18^{* * * *} \\
(0.05)\end{array}$ & & 0.308 & $\begin{array}{c}0.24 * * * \\
(0.08) \\
\end{array}$ & & & $\begin{array}{c}0.30^{* * *} \\
(0.06)\end{array}$ & 0.513 \\
\hline Triumphant & $\begin{array}{c}0.27 * * * \\
(0.09)\end{array}$ & & $\begin{array}{c}0.04 \\
(0.04)\end{array}$ & & 0.177 & $\begin{array}{c}0.26^{* * * *} \\
(0.08)\end{array}$ & & & $\begin{array}{c}0.24 * * * \\
(0.06)\end{array}$ & 0.486 \\
\hline Inspired & $\begin{array}{c}0.44 * * * \\
(0.09)\end{array}$ & & $\begin{array}{l}-0.01 \\
(0.05)\end{array}$ & & 0.479 & $\begin{array}{c}0.40 * * * \\
(0.08)\end{array}$ & & & $\begin{array}{c}0.10 \\
(0.06)\end{array}$ & 0.442 \\
\hline Secure & $\begin{array}{c}0.67 * * * \\
(0.10)\end{array}$ & & $\begin{array}{c}0.30 * * * \\
(0.06)\end{array}$ & & 0.340 & $\begin{array}{c}0.29 * * * \\
(0.10)\end{array}$ & & & $\begin{array}{l}0.16^{* * *} \\
(0.07)\end{array}$ & 0.323 \\
\hline Proud & $\begin{array}{c}0.30 * * * \\
(0.08)\end{array}$ & & & & 0.178 & $\begin{array}{c}0.58 * * * \\
(0.08)\end{array}$ & & & & 0.523 \\
\hline Believable & & & & & & $\begin{array}{c}0.26^{* * * *} \\
(0.10)\end{array}$ & & & & 0.126 \\
\hline Surprised & & & & $\begin{array}{c}0.30 * * * \\
(0.06)\end{array}$ & 0.188 & $\begin{array}{c}0.57 * * * \\
(0.17)\end{array}$ & & $\begin{array}{c}0.23 \\
(0.16)\end{array}$ & $\begin{array}{c}0.18 \\
(0.19)\end{array}$ & 0.197 \\
\hline Disgusted & & $\begin{array}{c}0.33 * * * \\
(0.05)\end{array}$ & & & 0.376 & $\begin{array}{c}0.04 \\
(0.09)\end{array}$ & & $\begin{array}{c}0.21 * * * \\
(0.05)\end{array}$ & & 0.311 \\
\hline Jealous & & $\begin{array}{c}0.32 * * * \\
(0.05)\end{array}$ & & & 0.292 & $\begin{array}{l}0.21 * * \\
(0.10)\end{array}$ & & $\begin{array}{c}0.23 * * * \\
(0.05)\end{array}$ & & 0.280 \\
\hline Aggravated & & $\begin{array}{c}0.36 * * * \\
(0.05)\end{array}$ & & & 0.433 & $\begin{array}{c}0.14 \\
(0.09)\end{array}$ & & $\begin{array}{c}0.26 * * * \\
(0.05)\end{array}$ & & 0.439 \\
\hline Frustrated & & $\begin{array}{c}0.39 * * * \\
(0.05)\end{array}$ & & & 0.450 & $\begin{array}{c}0.14 \\
(0.11)\end{array}$ & & $\begin{array}{c}0.30 * * * \\
(0.05)\end{array}$ & & 0.446 \\
\hline Angry & & $\begin{array}{c}0.38 * * * \\
(0.04)\end{array}$ & & & 0.603 & $\begin{array}{c}0.01 \\
(0.10) \\
\end{array}$ & & $\begin{array}{c}0.20 * * * \\
(0.05)\end{array}$ & & 0.401 \\
\hline Depressed & & $\begin{array}{c}0.20 * * * \\
(0.04)\end{array}$ & & & 0.295 & $\begin{array}{c}0.11 \\
(0.08)\end{array}$ & & $\begin{array}{c}0.17 * * * \\
(0.04)\end{array}$ & & 0.236 \\
\hline Sad & & $\begin{array}{c}0.08 * * \\
(0.03)\end{array}$ & & & 0.088 & $\begin{array}{l}-0.02 \\
(0.08)\end{array}$ & & $\begin{array}{l}0.10 * * \\
(0.04)\end{array}$ & & 0.197 \\
\hline Embarrassed & & & $\begin{array}{l}0.05 * * \\
(0.02)\end{array}$ & & 0.076 & & $\begin{array}{c}0.22 * * * \\
(0.05)\end{array}$ & & & 0.116 \\
\hline Ashamed & & & $\begin{array}{c}0.07 * * \\
(0.03)\end{array}$ & & 0.091 & & $\begin{array}{c}0.33 * * * \\
(0.05)\end{array}$ & & & 0.428 \\
\hline Guilty & & & $\begin{array}{c}0.16^{* * * *} \\
(0.03)\end{array}$ & & 0.272 & & $\begin{array}{c}0.45^{* * * *} \\
(0.05)\end{array}$ & & & 0.545 \\
\hline
\end{tabular}

Note: * indicates statistical significance at $p<0.10,{ }^{* *}$ significant at $p<0.05$, and ${ }^{* * *}$ at $p<0.01$

Standard errors are in parentheses. 
Table 5. Four Factor Model.

\begin{tabular}{|c|c|c|c|c|c|c|}
\hline Emotion & $\begin{array}{l}\text { Factor } \\
\text { Number }\end{array}$ & $\begin{array}{l}\text { Short-sighted } \\
\text { Negative } \\
\text { Factor }\end{array}$ & $\begin{array}{l}\text { Long-sighted } \\
\text { Negative } \\
\text { Factor }\end{array}$ & $\begin{array}{l}\text { Short-sighted } \\
\text { Positive } \\
\text { Factor }\end{array}$ & $\begin{array}{l}\text { Long-sighted } \\
\text { Positive } \\
\text { Factor }\end{array}$ & $\begin{array}{c}\text { Kaiser-Meyer-Olkin } \\
\text { Measure of Sampling } \\
\text { Adequacy }\end{array}$ \\
\hline \multicolumn{7}{|c|}{ Trustor } \\
\hline Appreciative & $\mathrm{F} 1$ & -0.42 & -0.07 & 0.78 & 0.12 & 0.70 \\
\hline Happy & F1 & -0.59 & 0.03 & 0.53 & 0.44 & 0.84 \\
\hline Content & $\mathrm{F} 1$ & -0.66 & 0.08 & 0.36 & 0.27 & 0.81 \\
\hline Cheerful & $\mathrm{F} 2$ & -0.41 & -0.02 & 0.48 & 0.57 & 0.78 \\
\hline Triumphant & F1 & -0.31 & 0.10 & 0.55 & 0.43 & 0.63 \\
\hline Inspired & $\mathrm{F} 2$ & -0.14 & -0.12 & 0.13 & 0.55 & 0.63 \\
\hline Secure & $\mathrm{F} 2$ & -0.33 & 0.04 & -0.06 & 0.83 & 0.64 \\
\hline Proud & $\mathrm{F} 2$ & -0.12 & -0.06 & 0.45 & 0.54 & 0.73 \\
\hline Believable & $\mathrm{F} 2$ & 0.17 & -0.21 & 0.35 & 0.54 & 0.46 \\
\hline Surprised & $\mathrm{F} 1$ & 0.07 & -0.23 & 0.67 & -0.12 & 0.38 \\
\hline Disgusted & F3 & 0.75 & 0.33 & -0.10 & -0.16 & 0.87 \\
\hline Jealous & $\mathrm{F} 3$ & 0.47 & 0.18 & 0.26 & -0.15 & 0.59 \\
\hline Aggravated & F3 & 0.86 & 0.03 & -0.19 & -0.18 & 0.78 \\
\hline Frustrated & $\mathrm{F} 3$ & 0.87 & 0.19 & -0.07 & -0.20 & 0.80 \\
\hline Angry & F3 & 0.93 & 0.06 & -0.08 & -0.20 & 0.83 \\
\hline Depressed & $\mathrm{F} 3$ & 0.83 & 0.32 & -0.09 & 0.04 & 0.78 \\
\hline Sad & $\mathrm{F} 3$ & 0.66 & 0.41 & -0.27 & 0.07 & 0.71 \\
\hline Embarrassed & $\mathrm{F} 4$ & 0.52 & 0.73 & -0.15 & 0.03 & 0.75 \\
\hline Ashamed & $\mathrm{F} 4$ & 0.21 & 0.89 & 0.07 & -0.11 & 0.68 \\
\hline Guilty & $\mathrm{F} 4$ & 0.00 & 0.79 & -0.12 & 0.07 & 0.46 \\
\hline \multicolumn{7}{|c|}{ Trustee } \\
\hline Appreciative & $\mathrm{F} 1$ & -0.27 & -0.01 & $\mathbf{0 . 8 8}$ & 0.11 & 0.88 \\
\hline Happy & $\mathrm{F} 1$ & -0.32 & 0.05 & 0.90 & 0.04 & 0.87 \\
\hline Content & $\mathrm{F} 1$ & -0.34 & 0.03 & 0.87 & 0.07 & 0.94 \\
\hline Cheerful & $\mathrm{F} 1$ & -0.32 & -0.01 & 0.84 & 0.10 & 0.94 \\
\hline Triumphant & $\mathrm{F} 1$ & -0.19 & 0.20 & 0.86 & 0.15 & 0.83 \\
\hline Inspired & $\mathrm{F} 1$ & -0.07 & -0.17 & 0.63 & 0.38 & 0.84 \\
\hline Secure & $\mathrm{F} 1$ & -0.29 & 0.09 & 0.63 & 0.46 & 0.86 \\
\hline Proud & $\mathrm{F} 1$ & -0.20 & -0.20 & 0.70 & 0.18 & 0.86 \\
\hline Believable & $\mathrm{F} 2$ & -0.13 & -0.03 & 0.31 & 0.69 & 0.74 \\
\hline Surprised & $\mathrm{F} 2$ & 0.30 & -0.21 & 0.34 & 0.43 & 0.42 \\
\hline Disgusted & $\mathrm{F} 3$ & 0.76 & 0.11 & -0.43 & 0.24 & 0.80 \\
\hline Jealous & F3 & 0.45 & -0.20 & -0.42 & 0.18 & 0.91 \\
\hline Aggravated & F3 & 0.77 & -0.20 & -0.42 & -0.13 & 0.87 \\
\hline Frustrated & $\mathrm{F} 3$ & 0.68 & -0.14 & -0.51 & -0.19 & 0.88 \\
\hline Angry & F3 & 0.62 & -0.11 & -0.62 & 0.07 & 0.86 \\
\hline Depressed & $\mathrm{F} 3$ & 0.83 & 0.05 & -0.29 & 0.02 & 0.84 \\
\hline Sad & F3 & 0.88 & 0.02 & -0.25 & -0.22 & 0.86 \\
\hline Embarrassed & $\mathrm{F} 4$ & 0.61 & 0.61 & 0.01 & 0.07 & 0.64 \\
\hline Ashamed & $\mathrm{F} 4$ & -0.02 & 0.94 & 0.05 & 0.01 & 0.48 \\
\hline Guilty & $\mathrm{F} 4$ & -0.08 & 0.92 & 0.04 & -0.06 & 0.61 \\
\hline
\end{tabular}


Table 6. Theoretical Emotional Activations Based on Trust Game Outcome Weights.

\begin{tabular}{|c|c|c|c|c|c|c|c|c|c|c|}
\hline \multirow[b]{3}{*}{ Subse } & \multicolumn{5}{|c|}{ Trustor } & \multicolumn{5}{|c|}{ Trustee } \\
\hline & \multicolumn{4}{|c|}{ Independent Variables } & \multirow[b]{2}{*}{ R-sq } & \multicolumn{4}{|c|}{ Independent Variables } & \multirow[b]{2}{*}{ R-sq } \\
\hline & A & $\mathrm{B}$ & $\mathrm{C}$ & D & & A & B & $\mathrm{C}$ & D & \\
\hline $\mathrm{U} 1$ & $\begin{array}{c}0.41 * * * \\
(0.09) \\
\end{array}$ & & & & 0.328 & $\begin{array}{c}0.33 * * * \\
(0.09)\end{array}$ & & & $\begin{array}{c}0.34 * * * \\
(0.08)\end{array}$ & 0.530 \\
\hline $\mathrm{U} 2$ & $\begin{array}{c}0.50^{* * *} \\
(0.07) \\
\end{array}$ & & $\begin{array}{c}0.14 * * * \\
(0.03)\end{array}$ & & 0.489 & $\begin{array}{c}0.28^{* * * *} \\
(0.06)\end{array}$ & & & $\begin{array}{c}0.26^{* * * *} \\
(0.05)\end{array}$ & 0.599 \\
\hline $\mathrm{U} 3$ & $\begin{array}{c}0.28 * * * \\
(0.09) \\
\end{array}$ & & & & 0.178 & $\begin{array}{c}0.43^{* * * *} \\
(0.07) \\
\end{array}$ & & & & 0.438 \\
\hline $\mathrm{U} 4$ & & & & $\begin{array}{c}0.26^{* * * *} \\
(0.07)\end{array}$ & 0.191 & $\begin{array}{c}0.72 * * * \\
(0.24)\end{array}$ & & $\begin{array}{l}0.41^{*} \\
(0.25)\end{array}$ & $\begin{array}{c}0.35 \\
(0.30)\end{array}$ & 0.176 \\
\hline U5 & & $\begin{array}{c}0.31 * * * \\
(0.03)\end{array}$ & & & 0.529 & $\begin{array}{c}0.12 \\
(0.08)\end{array}$ & & $\begin{array}{c}0.24 * * * \\
(0.04)\end{array}$ & & 0.451 \\
\hline U6 & & & $\begin{array}{c}0.10^{* * * *} \\
(0.03)\end{array}$ & & 0.190 & & $\begin{array}{c}0.35 * * * \\
(0.05)\end{array}$ & & & 0.444 \\
\hline
\end{tabular}

Note: * indicates statistical significance at $p<0.10,{ }^{* *}$ significant at $p<0.05$, and $* * *$ at $p<0.01$

Standard errors are in parentheses. 
Figure 1. Game Tree Showing Program Generated Decisions and Program Activated Emotions For All Decision Outcomes

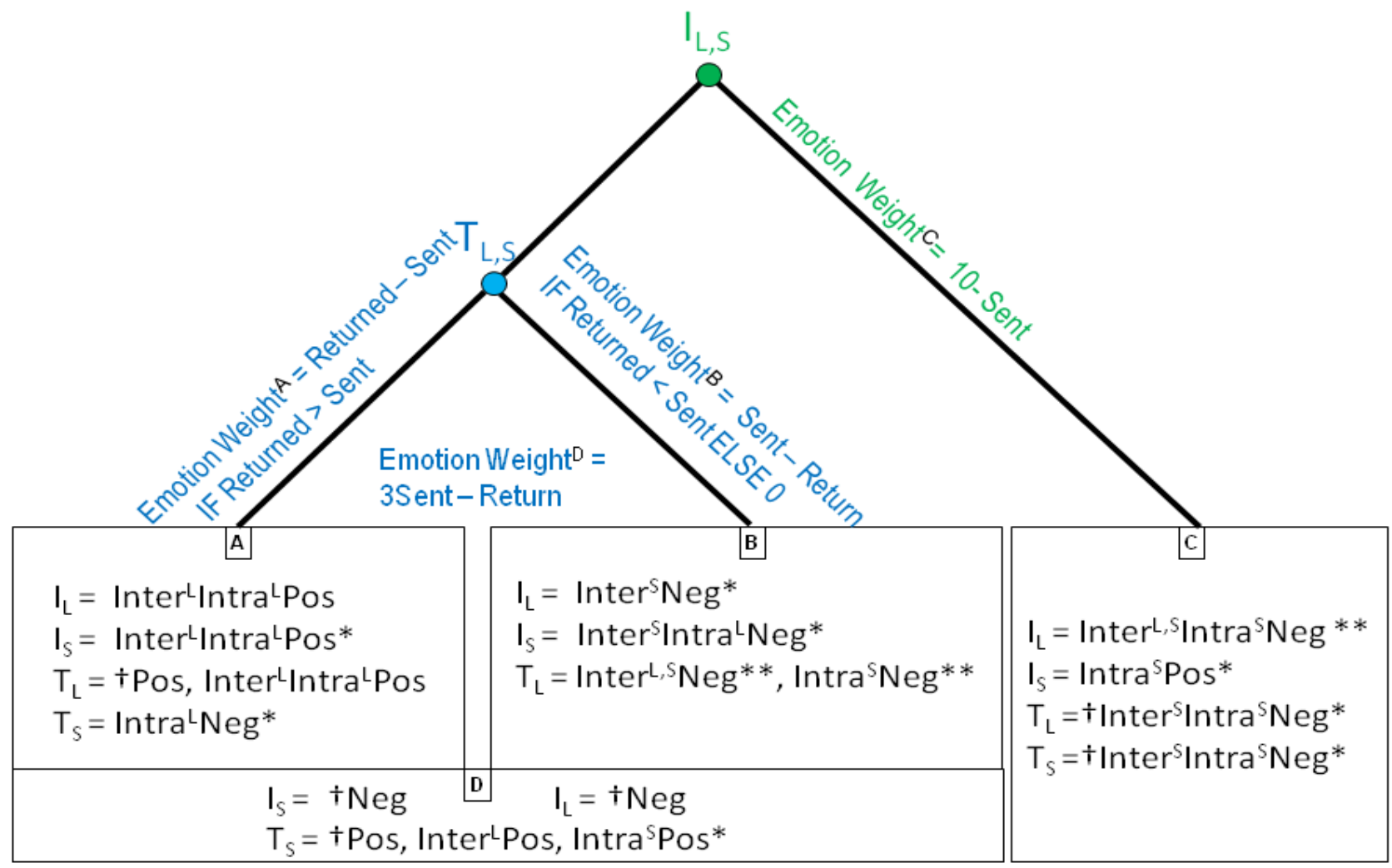

*Not including the exclusively long-sighted emotions ** Only the exclusively long-sighted emotions

† "surprise" (negative or positive)

$\mathrm{I}=$ trustor, $\mathrm{T}=$ trustee; Subscripts $(\mathrm{L}=$ long-sighted, $\mathrm{S}=$ short-sighted) denote programs (generating decisions and activating emotions consequent of decision-outcomes), superscripts denote location of programs $($ Intra $=$ in self, Inter $=$ in other $)$ targeted by emotions . 
Figure 2. Scatter Plot of the Amount Sent and the Amount Returned.

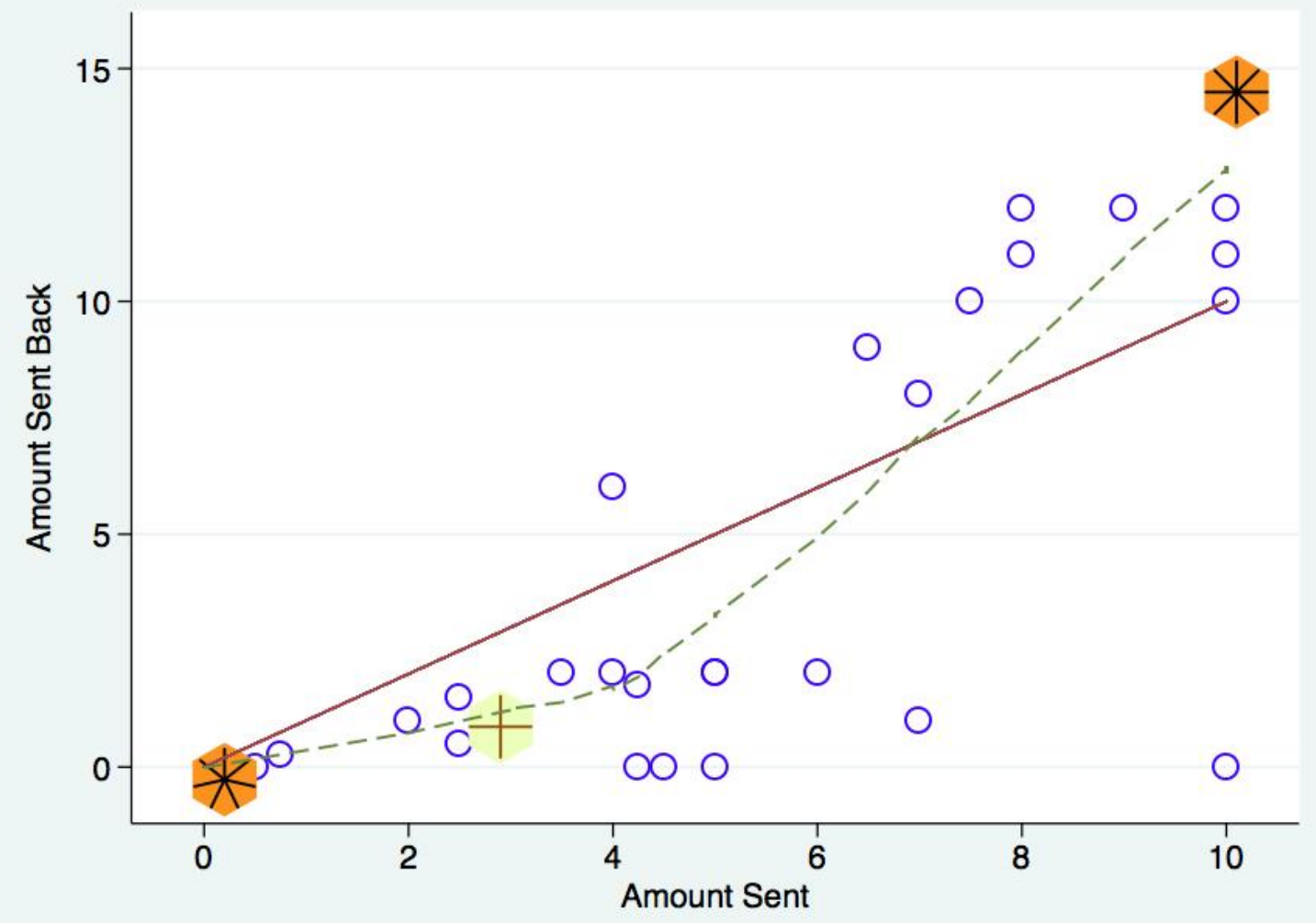


Figure 3. Schematic of the Computational Model of Weights and Their Linear Predictions of Emotional Activations

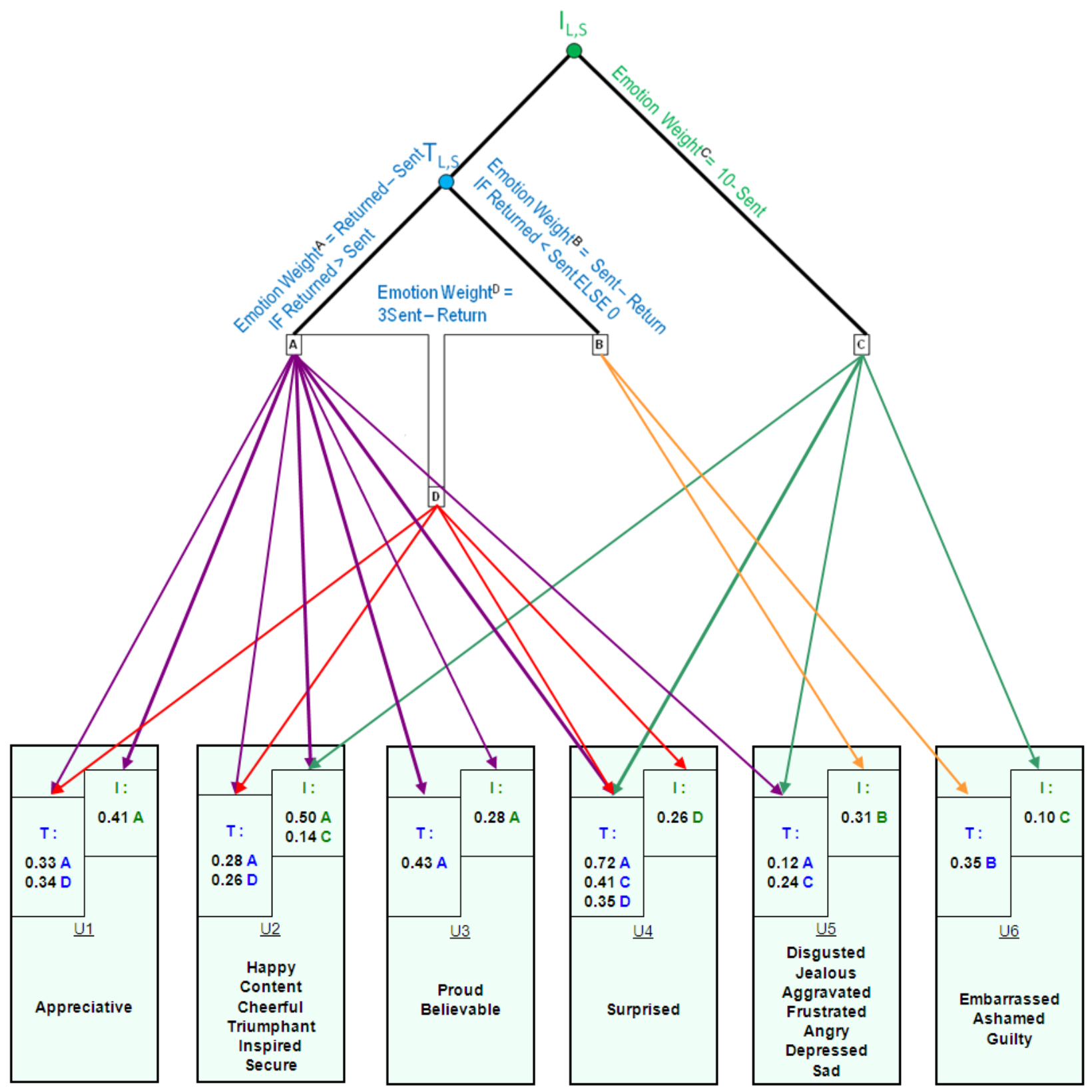

I=trustor, $\mathrm{T}=$ trustee; The coefficients from the seemingly unrelated regressions described in section 4.3 are reported. All weights, except for C \& D of T's U4, are significant at $<0.01$ 


\section{Appendix 1. Proposed Recalibrational Definitions of Emotions}

Appreciative: Appreciation (like "gratitude") is a positive emotion that is activated when either (or both) short-term or long-term goals are achieved as a consequence of another's nonopportunistic actions, and under conditions where similar non-opportunistic actions cannot be immediately produced for demonstrable reciprocation ${ }^{2}$. As an inter-personal ${ }^{3}$ positive emotion, the signal features of gratitude indicate to a receiver that the appreciative signaler acknowledges a presently unpayable debt while simultaneously indicating positive regard for the receiver's welfare and a willingness to engage in cooperative or helpful interaction. Gratitude effectively signals to a receiver that a cooperative relationship now with intent to deliver future returns has been established, a successful achievement from perspective of the receiver's long-term program. In turn, this input causes the receiver's long-term program to maintain its relative calibration (to competing programs), so as to ensure future successful interactions with the signaler.

Happy: Happiness is a positive emotion ${ }^{4}$ that is activated when either (or both) short-term or long-term goals are achieved ${ }^{5}$. As a positive emotion, it maintains the calibration of the successful program it is employed by (relative to the calibration of other competing programs) under choice dilemmas similar to the one which led to the success. Happiness also acts as a signal, giving it interpersonal functionality. When happiness is consequent of an interpersonal interaction and a happy individual signals her happiness to a receiver, it indicates a successful achievement from perspective of one or both of the signaler's short-term and long-term programs. In turn, this input causes the receiver's long-term program to maintain its relative calibration (to competing programs), so as to ensure future successful interactions with the signaler.

Content: Contentment is a positive emotion ${ }^{6}$ that is activated when either (or both) shortterm or long-term goals are achieved ${ }^{7}$. As a positive emotion which accompanies an increased sense of security, relief, or satiation, it maintains the calibration of the successful programs (relative to the calibration of other competing programs) under uncertain choice dilemmas similar to the one which led to the success. Contentment also acts as a signal, giving it interpersonal functionality. When contentment is consequent of an interpersonal interaction and a

\footnotetext{
${ }^{1}$ For similar perspectives on gratitude see Smith (1759), Trivers (1971), Hirshleifer (1987), Haidt (2003), Cosmides \& Tooby (2000), Tooby \& Cosmides (1990), Gallup (1998), McCullough et al. (2001), and Algoe et al. (2008).

${ }^{2}$ Also is consistent with Lazarus \& Lazarus (1994).

${ }^{3}$ However, for an intrapersonal account, see Simmel (1950) and Gouldner (1960)

${ }^{4}$ According to Shaver et al. (1987) this emotion is within a "joy" category along with contentment, cheerfulness, triumph, and overlapping subcategories including excitement, zest, contentment, pride, optimism, enthrallment, and relief.

${ }^{5}$ For a similar account specific to adaptive goals see Nesse \& Williams (1999), Cosmides \& Tooby (2000); for a similar account generalized to generic goals see Izard (1977), Smith \& Lazarus (1990), Lazarus (1991), Nesse (1990), de Catanzaro (1999), and Rayo \& Becker (2007).

${ }^{6}$ See footnote 4.

${ }^{7}$ For a similar account specific to adaptive goals see Ellsworth \& Smith (1988b), Izard (1977), Lazarus (1991), Nesse \& Williams (1999), and Cosmides \& Tooby (2000).
} 
content individual signals her contentment to a receiver, it indicates a successful achievement from perspective of one or both of the signaler's short-term and long-term programs. In turn, this input causes the receiver's long-term program to maintain its relative calibration (to competing programs), so as to ensure future successful interactions with the signaler.

Cheerful: Cheerfulness is a positive emotion ${ }^{8,9}$ that is activated when either (or both) short-term or long-term goals are achieved ${ }^{10}$. As a positive emotion ${ }^{11}$, it should maintain the calibration of the successful programs (relative to the calibration of other competing programs) it is employed by under choice dilemmas similar to the one which led to the success. Cheerfulness also acts as a signal (sometimes called "cheer"), giving it interpersonal functionality ${ }^{12}$. When cheerfulness is consequent of an interpersonal interaction and a cheerful individual signals her cheerfulness to a receiver, the receiver's long-term program recognizes cues of a successful achievement. This input causes the recipient's long-term program to sometimes creating a mirrored cheerfulness, but more importantly it causes the receiver's long-term program to maintain its relative calibration (to competing programs), so as to ensure future successful interactions with the signaler.

Triumphant: Triumph is a positive emotion ${ }^{13}$ that is activated when either (or both) short-term or long-term goals are achieved ${ }^{14}$ (or when success is recognized ${ }^{15}$ ), despite the experience of "effort" (a time-cumulative emotion produced by a program consequent of its forgone utilities) in pursuing those goals. As an intra-personal positive emotion ${ }^{16}$, it should maintain the calibration of the successful programs (relative to the calibration of other competing programs) under choice dilemmas similar to the one which led to the success (i.e. which may continue to require further effort).

Inspired: Inspiration (synonymous with "hope" ${ }^{" 17}$ ) is a positive emotion that is activated when events have indicated that either (or both) short-term or long-term goals are achieved. As an intra-personal positive emotion, it should maintain the calibration of the successful program (relative to the calibration of other competing program) under choice dilemmas similar to the one which led to the success, or increase the goal pursuit ${ }^{18}$ of successful program relative to a competing program.

\footnotetext{
${ }^{8}$ Alternatively, Frijda (2000) argues that cheerfulness is not an emotion but a mood that might not be tied to an antecedent and might endure over a long time.

${ }^{9}$ See footnote 4 .

${ }^{10}$ For a similar account specific to adaptive goals see Grinde (2002), also for a similar account of synonymous

"happiness" see footnote 5.

${ }^{11}$ See footnote 4.

${ }^{12}$ For similar perspective see Metts \& Bowers (1994).

${ }^{13}$ See footnote 4.

${ }^{14}$ For similar perspective see Sauter \& Scott (2007).

${ }^{15}$ See also de Catanzaro (1999, p.228) who writes that success "is energizing and can encourage effort".

${ }^{16}$ Alternatively, Sauter \& Scott (2007) argue that non-verbal vocalizations can signal one's triumphant state.

${ }^{17}$ For example, see Lazarus et al. (1980), and Smith \& Lazarus (1990).

${ }^{18}$ For a similar account see Thrash \& Elliot (2004).
} 
Secure: Security (similar to "confident" $" 19$ ) is a positive emotion ${ }^{20}$ that is activated when either (or both) short-term or long-term goals are achieved, bringing self the perspective that risks of not achieving the relevant goal are manageable or $\operatorname{low}^{21}$. As an intra-personal positive emotion which accompanies an increased sense of contentment, relief, or satiation, it should maintain the calibration of the successful program it is employed by (relative to the calibration of other competing programs) under choice dilemmas similar to the one which led to the success.

Proud: Pride is a positive emotion ${ }^{22,23}$ that is activated when long-term goals are achieved and when a choice dilemma put a social position at stake ${ }^{24}$. As an intra-personal ${ }^{25}$ positive emotion, it should maintain the calibration of the successful long-sighted program it is employed by (relative to the calibration of the competing short-sighted program) under choice dilemmas similar to the one which led to the success.

Believable: Believability (similar to "reliability" or "trustworthiness" 26 and "credibility"27) is an intrapersonal positive emotion that is activated when long-term goals are achieved because another has trusted self and self has acted in a trustworthy manner ${ }^{28}$. Without having first been trusted or "believed in", self cannot act in a way that will result in feeling believable. As an intra-personal positive emotion, it should maintain the calibration of the successful long-sighted program it is employed by (relative to the calibration of the competing short-sighted program) under choice dilemmas similar to the one which led to the success.

Surprised: Surprise is an intrapersonal positive ${ }^{29}$ or negative emotion ${ }^{30}$ that is activated when either (or both) short-term or long-term goals fail to be achieved despite expectations to the contrary. Negative surprise recalibrates one to be more likely to expect unfulfilled goals so that their goal systems do not inappropriately expect goals achieved in conditions where one's own actions were not to blame and so that their goal systems do not inappropriately expect goals achieved in conditions contingent on others' actions ${ }^{31}$. Negative surprise, sometimes called "shock" 32 may be accompanied by surprise reactions (i.e. cues) recognized by others and any of

\footnotetext{
${ }^{19}$ See Folkman \& Lazarus (1988) who see confidence as an upregulator of motivation to continue pursuit of a goal.

${ }^{20}$ See Shaver et al. (1987) who argue it is within a "loving" category along with feeling loved, warm, and trusting.

${ }^{21}$ For a similar account, see Schneier (2008).

${ }^{22}$ See footnote 4.

${ }^{23}$ For similar accounts see Fessler (2001) who argues pride is a "reward", and Nesse (1990) who argues pride brings "moral satisfaction".

${ }^{24}$ See also Gilbert \& Andrews (1998) how argue that pride is activated when social attention is directed towards one for actions which were appropriate, customary, and not excessive.

${ }^{25}$ Alternatively, an interpersonal account of pride has been argued by Fessler (1999), Chapman (1977), Chagnon (1983), Lindholm, (1982), and Weiner (1977). Another alternative meaning of pride described by Darwin (1872) is synonymous with "arrogance".

${ }^{26}$ For example see Maathuis et al. (2004).

${ }^{27}$ For example see Keller \& Aaker (1998).

${ }^{28}$ For a similar account see Maathuis et al. (2004), Hovland et al. (1953), Sternthal \& Craig (1982)

${ }^{29}$ See also Shaver et al. (1987) who argue that "amazement" and "astonishment" are emotions often associated with positive surprise.

${ }^{30}$ For a similar account see Wierbicka (1992). Alternatively, Ortony et al. (1988) and Ortony \& Turner (1990) argue that because it is not "valenced" as only positive or only negative, it is not an emotion.

${ }^{31}$ See also Izard (1991) and Tomkins (1962) who argue that surprise encourages adjustment of expectation.

${ }^{32}$ For example, see Ortony et al. (1988).
} 
several potential concomitant emotions (e.g. disappointment, sadness, anger) that can inform another that self's negative emotion was unexpected. Surprise, in and of itself, is not a signal designed for affecting inter-personal recalibration, however.

Disgusted: When another's actions have caused one to fail to achieve one's own shortterm and/or long-term goals, and when it is estimated that attempted recalibration of the other's responsible behaviors is not a worthwhile endeavor (e.g. recalibration attempts via anger or verbal communication would lead to more losses than gains), then the negative "disgust" emotion is activated, making the other an object of disgust. As a negative emotion, it downregulates the likelihood of interaction with the object of disgust ${ }^{33}$ under choice dilemmas $^{2}$ similar to the one which led to the failure of the program it is employed by. Disgust also acts as a signal, giving it interpersonal functionality. When a disgusted individual signals her disgust to a receiver, the receiver experiences a negative emotion which likewise downregulates the programs which were instrumental in the interaction's "failure" at achieving the signaler's program(s') goal(s).

Jealous: When, contrary to expectations, another's actions have caused one to fail to achieve one's own short-term and/or long-term goals, yet consequent on those actions the other has achieved their own goals ${ }^{34}$, then the negative "jealousy" emotion is activated ${ }^{35}$. As a negative emotion, it downregulates the competing program that has compromised the success of the program it is employed by. Coupled with this depressive outlook that should prohibit the repetition of past mistakes, jealousy encourages the recruitment of, and increase in behaviors like monitoring, vigilance, and aggression. These behaviors can alter the parameters of choice dilemmas to increase the chance of a jealous individual achieving her short-term and/or longterm goals. Jealousy also acts as a signal, giving it interpersonal functionality. When a jealous individual signals her jealousy to a receiver, the receiver experiences a negative emotion which likewise downregulates any of his programs which were instrumental in the interaction's "failure" at achieving the signaler's program(s') goal(s).

Aggravated: When another's actions prevent one from achieving one's own short-term and/or long-term goal(s), then aggravation can inhibit continued attempts under similar conditions $^{36}$. As a negative emotion, aggravation downregulates the unsuccessful program that it is employed by. Aggravation also acts as a signal, giving it interpersonal functionality. When an aggravated individual signals her aggravation to a receiver, the receiver experiences a negative emotion which likewise downregulates any of his programs which might have been instrumental

\footnotetext{
${ }^{33}$ For similar arguments about the social avoidance and distancing functions of disgust, see Haselton \& Ketelaar (2006), Tybur et al. (2009), and Rozin et al. (1993). For compatible argument about avoidance of risks, see Fessler et al., 2004. The generic feature of disgust, downregulating the likelihood of interaction with an object of disgust, also generalizes to mate and incest avoidance functions of disgust (e.g. see Westermarck, 1926; Tybur et al., 2009; Lieberman, et al., 2003; Fessler \& Navarette, 2003, 2004) as well as the toxin avoidance, contamination avoidance, and evacuation functions of disgusts (e.g., see Rozin et al., 1994; Haselton \& Ketelaar, 2006; Tybur et al., 2009; Curtis et al., 2004; Fessler, et al., 2004; Cosmides \& Tooby, 2000; Curtis \& Biran, 2001; and Levenson, 1999).

${ }^{34}$ For a similar account see Clanton \& Smith (1987), Parrot \& Smith (1993), and de Catanzaro (1999).

${ }^{35}$ While the antecedent of jealousy that we identify roughly maps onto the antecedent conditions that activate sexual jealousy (e.g. see Thornhill \& Palmer, 2000), we consider sexual jealousy a distinctly different emotion.

${ }^{36}$ For a similar account see Ortony et al. (1988).
} 
in an interaction's "failure" at achieving the signaler's program(s') goal(s). By downregulating problematic programs in the other, an aggravated individual can alter the parameters of her choice dilemmas, increasing the chance of achieving short-term and/or long-term goals.

Frustrated: When one's own and/or another's actions in pursuit of one's own short-term and/or long-term goals produced a failure (i.e. those goals could not be achieved), then frustration can inhibit continued attempts under similar conditions. ${ }^{37}$ As a negative emotion, frustration downregulates the unsuccessful program that it is employed by. Frustration also acts as a signal, giving it interpersonal functionality. When a frustrated individual signals her frustration to a receiver, the receiver experiences a negative emotion which likewise downregulates any of his programs which might have been instrumental in an interaction's "failure" at achieving the signaler's program(s') goal(s). By downregulating problematic programs in the other, an aggravated individual can alter the parameters of her choice dilemmas, increasing the chance of achieving the short-term and/or long-term goals.

Angry: When another's actions have caused one to fail to achieve one's own short-term and/or long-term goals, and when recalibration of the other's responsible behaviors via inflicted harm or restricted benefits might bring improvements, then the interpersonal negative "anger" emotion is activated ${ }^{38}$. As a negative emotion, it downregulates the program's likelihood of being activated relative to other competing programs under choice dilemmas like the one that led to the failure. By inflicting costs or restricting benefits to the other, an angered individual can alter the parameters of her choice dilemmas, increasing the chance of achieving her short-term and/or long-term goals. Anger also acts as a signal, giving it additional interpersonal functionality ${ }^{39}$. When an angry individual signals her anger to a receiver, the receiver experiences a negative emotion that likewise downregulates any of his programs which were instrumental in the interaction's "failure" at achieving the signaler's program(s') goal(s). When one's own actions in pursuit of one's own short-term and/or long-term goals produced the failure, then one's anger can be self-directed ${ }^{40}$. Acting as an intra-personal negative emotion, self-anger downregulates the competing program which has compromised the success of the program it is employed by.

Depressed: When one's own and/or another's actions in pursuit of one's own short-term and/or long-term goals produced a failure (i.e. those goals could not be achieved), then the negative "depression" emotion is activated. As a negative emotion, it downregulates the program's likelihood of being activated relative to other competing programs under choice

\footnotetext{
${ }^{37}$ See footnote 36.

${ }^{38}$ For similar interpersonal functional arguments, see Nesse (1990), Keltner et al. (1993), Allred et al. (1997), Fehr \& Gachter (2002), Cohen et al. (1996), Daly \& Wilson (1988), Luckenbill (1977), Toch (1969), Webster \& Kirkpatrick (2006), Sell (2006), Sell et al. (2009), Tooby et al. (2008), and Ortony et al. (1988).

${ }^{39}$ In addition to the signaling function that we identify, see arguments by Fessler (2010) and Frank (1988) for anger's "deterrence" effects on third parties.

${ }^{40}$ For similar accounts of a self-angry state, synonymous with "regretful", see Ellsworth \& Tong (2006), Zeelenberg \& Beattie (1997), Zeelenberg (1999), and Zeelenberg et al., (2008).
} 
dilemmas like the one that led to the failure. ${ }^{41}$ An additional feature of depressive symptoms is the focusing and rumination of thoughts pertaining to the failed goal pursuit ${ }^{42}$. In doing so, depression inflicts costs and/or restricts benefits to both self and to the other. A depressed individual alters the parameters of her choice dilemmas but in doing so does not directly increase the chance of achieving her short-term and/or long-term goals. Chances to achieve short-term and/or long-term goals may be improved through indirect signaling effects of depression, giving it interpersonal functionality. When a depressed individual signals her depression to a receiver, the receiver experiences a negative emotion which likewise downregulates any of his programs which were instrumental in the interaction's "failure" at achieving the signaler's program(s') goal(s). ${ }^{43}$ The receiver's long-term program also takes a depression signal as an input cue to upregulate its relative calibration (to competing programs), so as to ensure future successful interactions with the signaler.

Sad: When one's own and/or another's actions in pursuit of one's own short-term and/or long-term goals produced a failure (i.e. those goals could not be achieved), then the negative "sadness" emotion is activated. As a negative intra-personal emotion, it downregulates the unsuccessful program's likelihood of being activated relative to other competing programs under choice dilemmas like the one that led to the failure ${ }^{44}$. Displayed sadness can have mirrored effects on observers and in doing so can lead to a temporary paralysis of social interactions with the sad person. In doing so, sadness inflicts costs and/or restricts benefits to both self and to the other. A sad individual alters the parameters of her choice dilemmas but in doing so does not directly increase the chance of achieving her short-term and/or long-term goals. Chances to achieve short-term and/or long-term goals may be indirectly affected by signaling effects of sadness, giving it interpersonal functionality. When a sad individual signals her sadness to a receiver, the receiver experiences a negative emotion that likewise downregulates any of his programs which were instrumental in the interaction's "failure" at achieving the signaler's program(s') goal(s). ${ }^{45}$ The receiver's long-term program also takes a sad signal as an input cue to upregulate its relative calibration (to competing programs), so as to ensure future successful interactions with the signaler.

Embarrassed: When one's actions in pursuit of short-term goals produced a failure that affects one's character in so far as it conforms to social conventions ${ }^{46}$ (maintenance of which is

\footnotetext{
${ }^{41}$ For a similar account, see Darwin (1872), Lewis (1934), Nesse \& Williams (1999), Nesse (2000), and Hagen (2003).

${ }^{42}$ For a similar account see Nesse (1991), Taylor (1989), Gut (1989), and Nesse \& Williams (1999).

${ }^{43}$ Consistent with a downregulation of programs that led to another's depression, competing programs gain relative efficacy, which may in turn lead to behaviors that assist in achieving goals of the depressed persons goals (e.g. depression may function to recruit help, see Smith \& Lazarus, 1990; Hagen, 2003).

${ }^{44}$ For a similar account see Nesse (1990, 1999), Fredrickson (1998), and Smith \& Lazarus (1990)

${ }^{45}$ Consistent with a downregulation of programs that led to another's sadness, competing programs gain relative efficacy, which may in turn lead to behaviors that assist in achieving goals of the sad person (e.g. sadness may function to recruit help, see Smith \& Lazarus, 1990; Hagen, 2003).

${ }^{46}$ For a similar account, see Edelmann (1987), Keltner (1995), Keltner \& Buswell (1996, 1997), Keltner et al. (1997), Miller (1992), Miller \& Tangney (1994), Tangney (1992), and Buss (1980).
} 
pursuant to one's long-term goals with society at large), then the negative "embarrassment" emotion is activated. Acting as an intra-personal negative emotion, embarrassment recomputes the long-term value of conforming to social conventions relative to the short-term value of nonconformity and in doing so downregulates the short-term program which produced the previous non-conformist behaviors - thereby producing behaviors which effectively conform to social conventions and/or appease the offended ${ }^{47}$. Embarrassment also acts as a signal, giving it interpersonal functionality ${ }^{48}$. When an embarrassed individual signals she is embarrassed to an offended receiver (or a social group at large), the offended receiver(s) may recognize that preemptive recalibration has been taken on the part of the embarrassed signaler and that recalibrational emotions like anger or disgust, and their consequent behavioral outputs, may be unnecessary on the part of the offended.

Ashamed: When one's opportunistic actions in pursuit of short-term goals produced a failure that affects one's trusting or trustworthy character (maintenance of which is pursuant to one's long-term goals $)^{49}$, then the negative "shame" emotion is activated. Acting as an intrapersonal negative emotion, shame recomputes another's value relative to self ${ }^{50}$ and in doing so downregulates the short-term program which produced the previous opportunistic behaviors thereby producing behaviors which effectively increasing one's propensity to act in a trusting or trustworthy manner and/or appease the offended ${ }^{51}$. Shame also acts as a signal, giving it interpersonal functionality ${ }^{52}$. When a shameful individual signals ${ }^{53}$ she is ashamed to an offended receiver, the offended receiver may recognize that pre-emptive recalibration has been taken $^{54}$ on the part of the ashamed signaler and that recalibrational emotions (e.g. anger or disgust) and their consequent behavioral outputs, may be unnecessary on the part of the offended.

\footnotetext{
${ }^{47}$ For similar accounts of appeasement and reconciliations functions of embarrassment, see Goffman (1967), Miller \& Leary (1992), Eisenberg et al. (1989), Keltner (1995). Keltner \& Buswell (1997), Keltner et al., (1997), Gilbert \& Trower (1990), Scheff (1988), Semin \& Manstead (1982), Tangney et al. (1996), de Waal (1989), Shields et al., (1990), and de Jong, (1999).

${ }^{48}$ Borg et al. (1988), Izard (1977), Kaufman (1989), Lewis (1971), and Lewis (1990) have all argued that embarrassment is theoretically equivalent or highly similar to shame (with embarrassment being a "mild form" of shame). While we note the similarities, we agree with Tangney et al. (1996) who distinguish the experience of embarrassment with an accompanied sense of social exposure and, perhaps, a heightened concern for others' judgments - features that, unlike guilt and shame, also make it more difficult to experience privately.

${ }^{49}$ For similar accounts, see Buss (1980), Scheff (1988), Edelmann (1987), Keltner (1995), Keltner \& Buswell (1996, 1997), Keltner et al. (1997), Miller (1992), Miller \& Tangney (1994), and Tangney (1992).

${ }^{50}$ For a similar recomputational account, see Cosmides \& Tooby (2000), Tooby \& Cosmides (1990).

${ }^{51}$ For similar accounts of appeasement and reconciliations functions of embarrassment, see Miller \& Leary (1992), Eisenberg et al. (1989), Keltner \& Buswell (1996, 1997), Keltner et al., (1997), Gilbert \& Trower (1990), Scheff (1988), de Waal (1989), Shields et al., (1990), and de Jong, (1999). Alternatively, Nesse (1990) suggests that guilt enforces obedience to rules of social conduct.

${ }^{52}$ For a similar intrapersonal and interpersonal account of shame see Sznycer et al. (2011).

${ }^{53}$ Darwin, 1872 argued that blushing is one recognized cue that might be at work in this signaling, which he attributed to "self-attention... [about]... what others think of us..." (p.325).

${ }^{54}$ Perhaps also aiding in the recognition of the signaler's recalibration is accompanying regret and depression. For example, see Buss (1990), and Plutchik (1980).
} 
Guilty: When one's opportunistic actions ${ }^{55}$ in pursuit of short-term goals produced a failure that affects one's trusting or trustworthy character (maintenance of which is pursuant to one's long-term goals) $)^{56}$, then the negative "guilt" emotion is activated. Acting as an intrapersonal negative emotion, guilt downregulates the short-term program which produced the previous opportunistic behaviors - thereby producing behaviors which increase long-sighted goals $^{57}$ (like developing exchange relationships, issuing confessions and apologies, and appease the offended $)^{58}$. Unlike shame and embarrassment, guilt does not have strong signaling functions.

\section{References for Appendix 1.}

Algoe, S., \& Haidt, J., \& Gable, S. (2008). Beyond reciprocity: Gratitude and relationships in everyday life. Emotion, 8, 425-429.

Allred, K. G., Mallozzi, J. S., Matsui, F., \& Raia, C. P. (1997). The influence of anger and compassion on negotiation performance. Organizational Behavior \& Human Decision Processes, 70, 175-187.

Baumeister, R., Stillwell, A., \& Heatherton, T. (1994). Guilt: An interpersonal approach. Psychological Bulletin, 115(2), 243-267.

Baumeister, R. F., Stillwell, A. M., \& Heatherton, T. F. (1995). Personal narratives about guilt: Role in action control and interpersonal relationships. Basic and Applied Social Psychology, 17, 173-198.

Borg, I, Staufenbiel, T., \& Scherer, K.R. (1988). On the symbolic basis of shame. In K.R. Scherer (ed.), Facets of emotion: Recent research (pp.79-98). Hillsdale, NJ: Erlbaum.

Buss, A.H. (1980). Self-consciousness and Social Anxiety. San Francisco: W.H. Freeman.

Chagnon, Napoleon A. 1983. Yanomamo: The Fierce People (3rd ed.). New York: Holt, Rinehart and Winston.

Chapman, Robert L., ed. 1977. Roget's International Thesaurus (4th ed.). New York: Harper Collins.

Clanton, G. \& Smith, L.G. 1987. Jealousy. Lantham, MD: University Press of America

Cohen, D., Nisbett, R.E., Bowdle, B.F. \& Schwarz, N. (1996). Insult, aggression, and the southern culture of honor: an experimental ethnography. Journal of Personality and Social Psychology 70(5):946-960

Cosmides, L. and Tooby, J. (2000). Evolutionary psychology and the emotions In M. Lewis \& J. M. Haviland-Jones (Eds.), Handbook of Emotions, 2nd Edition. (pp. 91-115.) NY: Guilford.

\footnotetext{
${ }^{55}$ For an account of guilt being produced by one's actions that appear "wrong" or immoral to others, see Baumeister et al. (1994, 1995), and Tangney (1991).

${ }^{56}$ For a similar account see Baumeister et al. (1995), Ketelaar \& Au (2003), de Hooge et al. (2007), and Frank (1988).

${ }^{57}$ For a similar account see Ketelaar \& Au (2003), Zeelenberg (1999), Zeelenberg et al. (2008), Sznycer et al. (2011), and Frank (1988).

${ }^{58}$ For a similar account see Wicker et al. (1983), de Hooge et al. (2007), Baumeister et al. (1994, 1995), Ohtsubo \& Watanabe (2009), Ketelaar \& Au (2003), Tangney et al. (1996), and McCullough et al. (2001). Additionally, Wicker et al. (1983) argues that guilt in an offender stops the infliction of costs on others, while Tangney (1991) and Leith $\&$ Baumeister argue that guilt increases the offender's empathy.
} 
Curtis, V., \& Biran, A. (2001). Dirt, disgust, and disease: Is hygiene in our genes?. Perspectives in Biology and Medicine, 44, 17-31.

Daly, M. \& Wilson, M. (1988). Homicide. New York: de Gruyter.

Darwin, C. (1872). Expression of Emotions in Man and Animals. Chicago: University of Chicago Press. [1965 version]

de Catanzaro, D. (1999). Motivation and Emotion: Evolutionary, Physiological, Developmental, and Social Perspectives. Upper Saddle River, NJ: Prentice Hall (Pearson Education).

de Hooge, I. E., Zeelenberg, M., \& Breugelmans, S. M. (2007). Moral sentiments and cooperation: Differential influences of shame and guilt. Cognition \& Emotion, 21(5), 10251042.

de Jong, P.J. (1999). Communicative and remedial effects of social blushing. Journal of Nonverbal Behavior 23(3)197-217

de Waal, F.B.M. (1989). Peacemaking Among Primates. Cambridge: Harvard University Press

Edelmann RJ (1987): Psychology of Embarrassment. Chichester, UK: John Wiley.

Eisenberg N, Fabes RA, Miller PA, Fultz J, Shell R, Mathy RM, Reno RR (1989): Relation of sympathy and personal distress to prosocial behavior: A multimethod study. Journal of Personality and Social Psychology 57:55-66.

Ellsworth, P. C. \& Smith, C. A. (1988b). Shades of joy: patterns of appraisal differentiating pleasant emotions. Cognition and Emotion 2, 301-331.

Ellsworth, P.C. \& Tong, M.W. (2006). What does it mean to be angry at yourself? Categories, appraisals, and the problem of language. Emotion 6(4):572-586

Fehr, E. \& Gächter, S. (2002). Altruistic punishment in humans. Nature 415:137-40.

Fessler, D. M. T. (2010): Madmen: An evolutionary perspective on anger and men's violent responses to transgression. In: M. Potegal, G. Stemmler \& C. Spielberger (eds): Handbook of Anger: Constituent and Concomitant Biological, Psychological, and Social Processes. Pp.361-381

Fessler, D.M.T. (1999). Toward an understanding of the universality of second order emotions. In Beyond Nature or Nurture: Biocultural Approaches to the Emotions, A. Hinton, ed. pp.75116. New York: Cambridge University Press

Fessler, D.M.T. (2001). Emotions and cost-benefit assessment: the role of shame and self-esteem in risk taking. In Bounded Rationality: the Adaptive Toolbox Gerd Gigerenzer and Reinhard Selten (Eds.) Cambridge, Massachusetts: MIT Press

Fessler, D. M. T. (2010): Madmen: An evolutionary perspective on anger and men's violent responses to transgression. In: M. Potegal, G. Stemmler \& C. Spielberger (eds): Handbook of Anger: Constituent and Concomitant Biological, Psychological, and Social Processes. Pp.361-381

Fessler, D. M. T., \& Navarrete, C. D. (2003). Domain-specific variation in disgust sensitivity across the menstrual cycle. Evolution and Human Behavior, 24, 406-417.

Fessler, D.M.T. and Navarrete, C.D. (2004) Third-party attitudes toward sibling incest: Evidence for Westermarck's Hypotheses. Evolution and Human Behavior 25(5):277-294.

Fessler, D. M. T., Pillsworth, E. G., \& Flamson, T. J. (2004). Angry men and disgusted women: An evolutionary approach to the influence of emotions on risk taking. Organizational Behavior and Human Decision Processes, 95, 107-123.

Folkman, S., and Lazarus, R.S. (1988). The relationship between coping and emotion: Implications for theory and research. Social Science \& Medicine 26(3):309-317

Frank, R.L. (1988). Passions Within Reason: the Strategic Role of the Emotions. NY: Norton. 
Fredrickson, B.L. (1998). What good are positive emotions? Review of General Psychology, 2, 300-319.

Frijda, N.H. (2000). "The Psychologist's Point of View', in M. Lewis and J.M. Haviland-Jones (eds) Handbook of Emotions, 2nd edn, pp. 59-74. New York: Guilford.

Gallup, G. G. (1998). Self-awareness and the evolution of social intelligence. Behavioural Processes, 42, 239-247.

Gilbert P, Trower P (1990). The evolution and manifestation of social anxiety. In Crozier WR (ed): Shyness and Embarrassment: Perspectives From Social Psychology. Cambridge: Cambridge University Press, pp 144-179.

Gilbert, P. \& Andrews, B. (1998). Shame: Interpersonal Behavior, Psychopathology, and Culture. Series in Affective Science. New York: Oxford University Press.

Goffman E (1967). Interaction Ritual: Essays on Face-to-Face Behavior. Garden City, NY: Anchor.

Gouldner, A. W. (1960). The norm of reciprocity: A preliminary statement. American Sociological Review, 25, 161-178.

Grinde, B. (2002). Happiness in the perspective of evolutionary psychology. Journal of Happiness Studies 3: 331-354

Gut, E. (1989). Productive and Unproductive Depression: Success or Failure of a Vital Process. New York: Basic Books

Hagen, E. (2003). The Bargaining Model of Depression. In Genetic and Cultural Evolution of Cooperation, P. Hammerstein (Ed.) pp. 95-123.MIT Press.

Haidt, J. (2003a). The moral emotions. In R. J. Davidson, K. R. Scherer, \& H. H. Goldsmith (Eds.), Handbook of Affective Sciences. Oxford: Oxford University Press.(pp. 852-870).

Haselton, M.G. \& Ketelaar, T. (2006). Irrational emotions or emotional wisdom? The evolutionary psychology of emotions and behavior. In J. P. Forgas (Ed.), Hearts and minds: Affective influences on social cognition and behavior (pp. 21-40). New York: Psychology Press

Hirschleifer, J. (1987). On the emotions as guarantors of threats and promises. in J. Dupre, (ed.) The Latest On the Best: Essays on Evolution and Optimality (pp.307-326). Boston: MIT Press.

Hovland, C.I., Janis, I.L., \& Kelley, H. (1953). Communication and Persuasion. New Haven, CT: Yale University Press.

Izard, C.E. (1977). Human Emotions. New York: Plenum

Izard, C.E. (1991). The Psychology of Emotions. New York: Plenum Press.

Kaufman, G. (1989). The Psychology of Shame: Theory and Treatment of Shame-based Syndromes. New York: Springer.

Keller, K.I, and Aaker, D.A. (1998). Corporate-level marketing: the impact of credibility on a company's brand extensions. Corporate Reputation Review 1(4):356-378

Keltner D (1995): The signs of appeasement: Evidence for the distinct displays of embarrassment, amusement, and shame. Journal of Personality and Social Psychology 68:441-454.

Keltner D, Buswell BN (1996): Evidence for the distinctness of embarrassment, shame, and guilt: A study of recalled antecedents and facial expressions of emotion. Cognition and Emotion 10:155-171.

Keltner D, Buswell BN (1997): Embarrassment: Its distinct form and appeasement functions. Psychological Bulletin. 122(3):250-270 
Keltner, D., Ellsworth, P. C., \& Edwards, K. (1993). Beyond simple pessimism: Effects of sadness and anger on social perception. Journal of Personality and Social Psychology, 64, 740-752.

Keltner, D., Young, R.C., \& Buswell, B.N. (1997). Appeasement in human emotion, social practice, and personality. Aggressive Behavior 23:359-374.

Ketelaar, T. \& Au, W. T. (2003). The effects of guilty feelings on the behavior of uncooperative individuals in repeated social bargaining games: An Affect-as-information interpretation of the role of emotion in social interaction. Cognition \& Emotion, 17, 429-453

Lazarus, R. S. (1991). Emotion and adaptation. New York: Oxford University Press

Lazarus, R. S., \& Lazarus, B. N. (1994). Passion and Reason: Making Sense of Our Emotions. New York: Oxford University Press.

Lazarus, R.S., Kanner, A.D., and Folkman, S. (1980). Emotions; A Cognitive phenomenological analysis. in R. Plutchik and H. Kellerman (eds.) Emotion: Theory, Research, and Experience. Vol. 1 Theories of Emotion. (pp.189-217). New York: Plenum Press

Leith, K. P., \& Baumeister, R. F. (1998). Empathy, shame, guilt, and narratives of interpersonal conflicts: Guilt-prone people are better at perspective taking. Journal of Personality, 66, 137.

Levenson, R.W. (1999). The Intrapersonal functions of emotion. Cognition and Emotion. 13(5):481-504.

Lewis A. J. (1934). Melancholia: A clinical survey of depressive states. Journal of Mental. Science 80: 1-43.

Lewis, H.B. (1971). Shame and Guilt in Neurosis. New York: International Universities Press.

Lewis, H.B. (1990). Thinking and feeling - the elephant's tail. In C.A. Maher, M Schwebel, \& N.S. Fagley (eds.), Thinking and Problem-solving in the Developmental Process: International Perspectives (the WORK) (pp.89-110). Hillsdale, NJ: Erlbaum.

Lieberman, D., Tooby, J. \& Cosmides, L. (2003). Does morality have a biological basis? An empirical test of the factors governing moral sentiments regarding incest. Proceedings of the Royal Society of London: B Biological Sciences, 270, 819-826.

Lindholm, Cherry. 1982. Swat Pukhtun Family as a Political Training Ground. South Asia Occasional Papers and Theses. Ithaca. 8:51-60.

Luckenbill, D. (1977). Criminal homicide as a situated transaction. Social Problems, 25, 176-186

Maathius O., Rodenburg J., Sikkel D. (2004), Credibility, Emotion or Reason? Corporate Reputation Review, 6(4):333-345

McCullough, M. E., Kilpatrick, S. D., Emmons, R. A., \& Larson, D. B. (2001). Is gratitude a moral affect? Psychological Bulletin, 127, 249-266.

Metts, S. \& Bowers, J. (1994). Emotion in interpersonal communication. In Handbook of Interpersonal Communication. Mark Knapp, Gerald Miller (eds.) Thousand Oaks, CA: Sage.

Miller RS (1992): The nature and severity of self reported embarrassing circumstances. Personality and Social Psychology Bulletin 18:190-198.

Miller R.S., \& Tangney, J.P. (1994): Differentiating embarrassment from shame. Journal of Social and Clinical Psychology 13:273-287.

Miller, R. S., \& Leary, M. R. (1992). Social sources and interactive functions of embarrassment. In M. Clark (Ed.), Emotion and Social Behavior (pp. 322-339). New York: Russell Sage Foundation.

Nesse, R.M. (1990). Evolutionary explanations of emotions. Human Nature 1(3):261-289. 
Nesse, R.M. (1991). What good is feeling bad? The evolutionary benefits of psychic pain. The Sciences November/December:30-37

Nesse, R.M. (2000). Is Depression an Adaptation? Archives of General Psychiatry 57:14-20.

Nesse, R. M., Williams, G. C. (1999). Why We Get Sick: The New Science of Darwinian Medicine. New York: Random House

Ohtsubo, Y., \& Watanabe, E. (2009). Do sincere apologies need to be costly? Test of a costly signaling model of apology. Evolution and Human Behavior, 30(2),114-123.

Ortony, A., \& Turner, T. J. (1990). What's basic about basic emotions? Psychological Review, 97, 315-331.

Ortony, A., Clore, G. L. \& Collins, A. (1988) The Cognitive Structure of Emotions. Cambridge, NY: Cambridge University Press.

Parrot, W.G. \& Smith, R.H. (1993). Distinguishing the experiences of envy and jealousy. Journal of Personality and Social Psychology. 64:906-920

Plutchik, R. (1980). Emotion: A Psychoevolutionary Synthesis. New York: Harper \& Row.

Rayo, L.\& Becker, G.S. (2007). Habits, peers, and happiness: an evolutionary perspective. American Economic Review, 97(2):487-491

Rozin, P., Haidt, J., \& McCauley, C. R. (1993). Disgust. In M. Lewis \& J. Haviland (Eds.), Handbook of Emotions (pp. 575-594). New York: Guilford Press.

Rozin, P., Lowery, L., \& Ebert, R. (1994). Varieties of disgust faces and the structure of disgust. Journal of Personality and Social Psychology, 66:870-881.

Sauter, D.A. \& Scott, S.K. (2007). More than one kind of happiness: can't we recognize vocal expressions of different positive states? Motivation and Emotion 31:192-199

Scheff TJ (1988): Shame and conformity: The deference emotion system. American Sociological Review 53:395-406.

Schneier, B. (2008). The psychology of security. In The Proceedings of Africacrypt 2008; Lecture Notes in Computer Science 5023, (pp. 50-79), S. Vaudenay (Ed.). Berlin: SpringerVerlag.

Sell, A. (2006). Regulating welfare tradeoff ratios: three tests of an evolutionary computational model of human anger. Doctoral dissertation, Department of Psychology, University of California, Santa Barbara.

Sell, A., Tooby, J., \& Cosmides, L. (2009). Formidability and the logic of human anger. Proceedings of the National Academy of Science, 106(35), 15073-78.

Semin GR, Manstead ASR (1982): The social implications of embarrassment displays and restitution behavior. European Journal of Social Psychology 12:367-377.

Shaver, P., Schwartz, J., Kirson, D., \& O’Connor, C. (1987). Emotion knowledge: further exploration of a prototype approach. Journal of Personality and Social Psychology 52(6):1061-1086.

Shields, S.A., Mallory, M.E., \& Simon, A. (1990). The experience and symptoms of blushing as a function of age and reported frequency of blushing. Journal of Nonverbal Behavior, 14, $171-187$.

Simmel, G. (1950). The sociology of Georg Simmel. Glencoe, IL: Free Press.

Smith, A. (1759). The Theory of Moral Sentiments. 2000 edition. NY: Prometheus Books.

Smith, C.A. \& Lazarus, R.S. (1990). Emotion and adaptation. In Handbook of Personality: Theory and Research edited by L.A. Pervin. pp.609-637 New York: Guilford.

Sternthal, B. \& Craig, C.S. (1982). Consumer Behaviour: An Informatic Processing Perspective. Englewood Cliffs, NJ: Prentice Hall. 
Sznycer, D., Takemura, K., Delton, A. W., Sato, K., Robertson, T., \& Tooby, J. (2011). Crosscultural differences and similarities in proneness to shame: An adaptationist and ecological approach. (submitted for publication)

Tangney, J. P. (1991). Moral affect: The good, the bad, and the ugly. Journal of Personality and Social Psychology 61(4):598-607

Tangney, J.P. (1992): Situational determinants of shame and guilt in young adulthood. Personality and Social Psychology Bulletin 18:199-206.

Tangney, J. P., Miller, R. S., Flicker, L., \& Barlow, D. H. (1996). Are shame, guilt, and embarrassment distinct emotions? Journal of Personality and Social Psychology, 70, 1256 1269.

Taylor, S. E. (1989). Positive Illusions: Creative self-deception and the healthy mind. New York: Basic Books

Thornhill, R. \& Palmer, C.T. (2000). A Natural History of Rape: Biological Bases of Sexual Coercion. Cambridge MA: MIT Press

Thrash, T.M., \& Elliot, A.J. (2004). Inspiration: core characteristics, component processes, antecedents, and function. Journal of Personality and Social Psychology, 87(6):957-973.

Toch, H. (1969). Violent men. Chicago: Aldine

Tomkins, S.S. (1962). Affect, imagery, consciousness: Vol. 1 The positive affects. New York: Springer

Tooby, J. \& Cosmides, L. (1990). The past explains the present: Emotional adaptations and the structure of ancestral environments. Ethology and Sociobiology, 11, 375-424.

Tooby, J., Cosmides, L., Sell, A., Lieberman, D., and Sznycer, D. (2008). Handbook of Approach and Avoidance Motivation, chapter Internal Regulatory Variables and the Design of Human Motivation: A Computational and Evolutionary Approach, pages 251-271. Mahwah, NJ: Lawrence Erlbaum Associates.

Tybur, J.M., Lieberman, D., \& Griskevicius, V. (2009). Microbes, mating, and morality: individual differences in three functional domains of disgust. Journal of Personality and Social Psychology 97(1): 103-122

Webster, G.D. \& Kirkpatrick, L.A. (2006). Behavioral and self-reported aggression as a function of domain-specific self-esteem. Aggressive Behavior 32(1):17-27

Weiner, Annette B. (1988). The Trobrianders of Papua New Guinea. New York: Holt, Rinehart and Winston.

Westermarck, E. (1926). A Short History of Marriage. New York: Macmillan \& Co.

Wicker, F. W., Payne, G. C., \& Morgan, R. D. (1983). Participant descriptions of guilt and shame. Motivation and Emotion, 7(1), 25-39.

Wierbicka, A. (1992). Defining emotion concepts. Cognitive Science, 16, 539, 581.

Zeelenberg, M. (1999). Anticipated regret, expected feedback and behavioral decision-making. Journal of Behavioral Decision Making, 12:93-106.

Zeelenberg, M., \& Beattie, J. (1997). Consequences of regret aversion 2: Additional evidence for effects of feedback on decision making. Organizational Behavior and Human Decision Processes, 71, 1-1

Zeelenberg, M., Nelissen, R.M.A., Breugelmans, S.M., \& Pieters, R. (2008). On emotion specificity in decision making: Why feeling is for doing. Judgment and Decision Making $3(1): 18-27$ 


\section{Appendix 2. Instructions}

This is an experiment in the economics of decision-making. Various research agencies have provided funds for this research. The currency used in the experiment is experimental dollars, and they will be converted to U.S. Dollars at a rate of 1 experimental dollars to 1_dollar. At the end of the experiment your earnings will be paid to you in private and in cash. It is very important that you remain silent and do not look at other people's work. If you have any questions, or need assistance of any kind, please raise your hand and an experimenter will come to you. If you talk, laugh, exclaim out loud, etc... you will be asked to leave and you will not be paid. We expect, and appreciate, you adhering to these policies.

\section{THE EXPERIMENT}

The participants in today's experiment will be randomly assigned into two-person groups. In addition to the group assignment each participant will also be randomly assigned to a specific type in the group, designated as Person 1 or Person 2. You and the other participant in your group will make choices that will determine your payoffs. The experiment consists of two decision stages.

In stage 1, Person 1 receives $\$ 10$ and then decides how many dollars to send to Person 2. Person 1 can send none, more than none, or all of the $\$ 10$ to Person 2. The amount sent by Person 1 is tripled before reaching Person 2. In stage 2, Person 2 decides how many of the dollars they received to send back to Person 1. Person 2 can send none, more than none, or all of the amount received back to Person 1. At that point the experiment is over.

Next we describe in details the decisions made by both persons in each stage of the experiment.

Stage 1: Person 1 receives $\$ 10$ and then decides how many dollars to send to Person 2. Person 1 can send none, more than none, or all of the $\$ 10$. Person 1 enters the amount sent to Person 2 in the box labeled "The amount sent by Person 1" below. Person 1 keeps any amount that is not sent to Person 2. The amount sent by Person 1 is tripled before reaching Person 2.

Person 1 can send none, more than none, or all of $\$ 10$ to Person 2.

Person 2 can send back $20 \%$, more than $20 \%$, or all of the multiplied amount received from Person 1

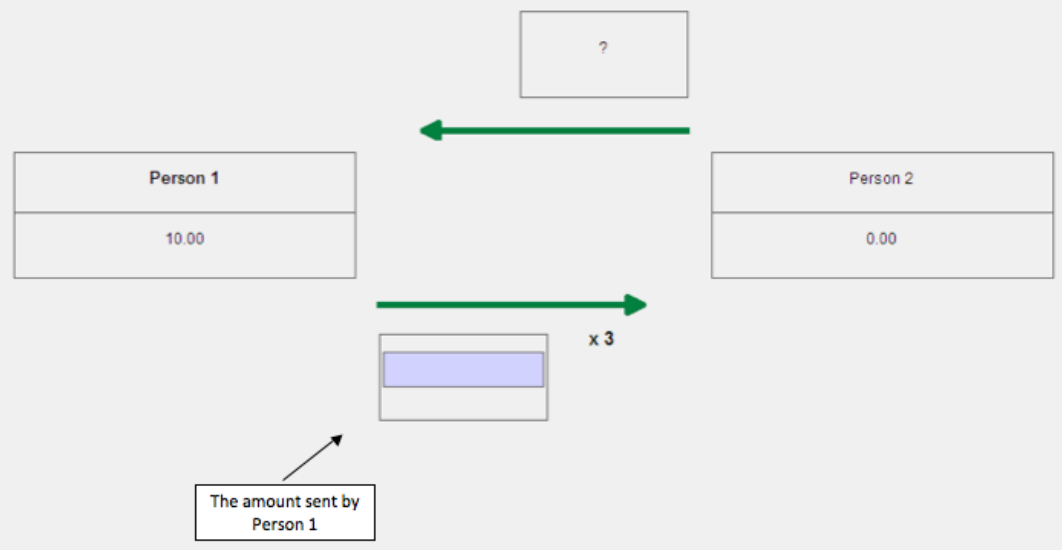

confim

Stage 2: After learning the amount sent by Person 1, Person 2 decides how many dollars to send back to Person 1. Person 2 can send none, more than none, or all of the amount in Person 2's account at that time. Person 2 enters the 
amount sent back to Person 1 in the box labeled "The amount sent back by Person 2" below. The amount sent back by Person 2 is NOT multiplied. Person 2 keeps any amount that is not sent back to Person 1 .

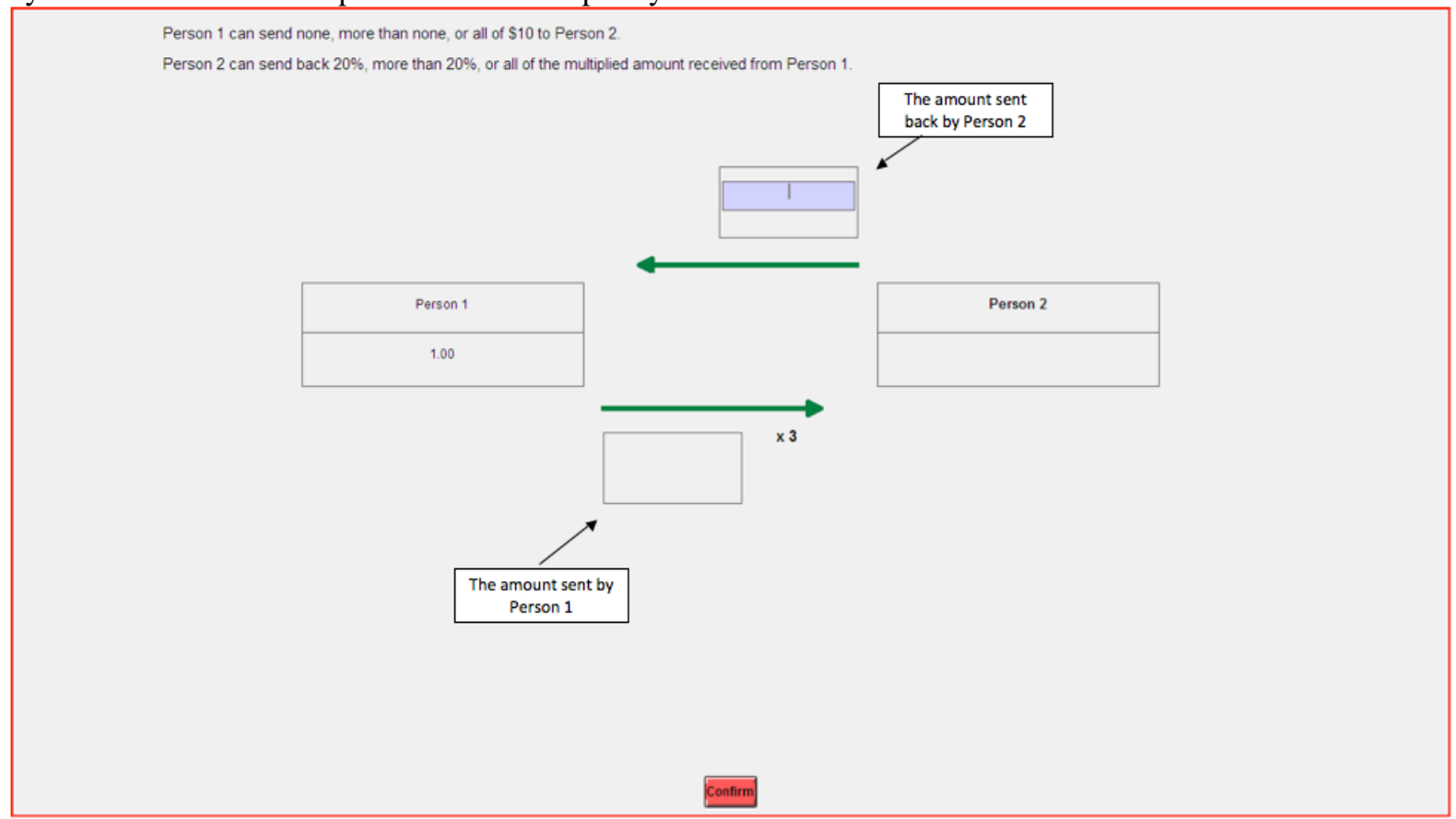

Finally, at the end of the Stage 2 the total earnings are reported to each person.

- Person 1's earnings will equal $\$ 10$ less the amount sent to Person 2 plus the amount sent back by Person 2.

- Person 2's earning will equal three times the amount sent by Person 1 less the amount sent back to Person 1.

Please record the decisions and your earnings on your record sheet under the appropriate heading.

\section{SUMMARY}

The computer will assign you and one other participant to a two-person group, consisting of Person $\mathbf{1}$ and Person 2. In stage 1, Person 1 receives $\$ 10$ and then decides how many dollars to send to Person 2. Person 1 can send none, more than none, or all of the $\$ 10$. The amount sent by Person 1 is tripled. In stage 2, Person 2 decides how many dollars to send back to Person 1. Person 2 can send none, more than none, or all of the amount in Person 2's account at that time. At the end of Stage 2 the total earnings are reported to each person. This experiment is now over and your earnings will be part of the total you will be paid.

\section{QUIZ}

Before starting, we want you to answer some questions regarding the experiment to be sure you understand what will follow. After five minutes an experimenter will return to privately review your answers. Afterwards you will participate in the experiment only one time.

1. True or false: the amount sent by Person 1 is tripled before reaching Person 2's account.

2. True or false: the amount sent back by Person 2 is tripled before reaching Person 1's account.

3. What is the largest amount Person 1 can send to Person 2?

4. What is the smallest amount Person 2 can send back to Person 1 ?

5. If Person 1 sent $\$ 4.20$ to Person 2, what is largest amount Person 2 can send back to Person 1 ?

6. If Person 1 sent $\$ 9.00$ to Person 2 , what is smallest amount Person 2 can send back to Person 1 ?

7. True or false: If Person 1 sends something to Person 2, then Person 2 has to send something back to Person 1.

8. True or false: you will participate in this experiment only one time. 


\section{Economic Science Institute Working Papers}

\section{1}

11-11 Pedro Rey-Biel, P., Sheremeta, R. and Uler, N. (Bad) Luck or (Lack of) Effort?: Comparing Social Sharing Norms between US and Europe.

11-10 Deck, C., Porter, D., Smith, V. Double Bubbles in Assets Markets with Multiple Generations.

11-09 Kimbrough, E., Sheremeta, R., and Shields, T. Resolving Conflicts by a Random Device.

11-08 Brañas-Garza, P., García-Muñoz, T., and Hernan, R. Cognitive effort in the Beauty Contest Game.

11-07 Grether, D., Porter, D., and Shum, M. Intimidation or Impatience? Jump Bidding in On-line Ascending Automobile Auctions.

11-06 Rietz, T., Schniter, E., Sheremeta, R., and Shields, T. Trust, Reciprocity and Rules.

11-05 Corgnet, B., Hernan-Gonzalez, R., and Rassenti, S. Real Effort, Real Leisure and Real-time Supervision: Incentives and Peer Pressure in Virtual Organizations.

11-04 Corgnet, B. and Hernán-González R. Don’t Ask Me If You Will Not Listen: The Dilemma of Participative Decision Making.

11-03 Rietz, T., Sheremeta, R., Shields, T., Smith, V. Transparency, Efficiency and the Distribution of Economic Welfare in Pass-Through Investment Trust Games.

11-02 Corgnet, B., Kujal, P. and Porter, D. The Effect of Reliability, Content and Timing of Public Announcements on Asset Trading Behavior.

11-01 Corgnet, B., Kujal, P. and Porter, D. Reaction to Public Information in Markets: How Much Does Ambiguity Matter?

2010

10-22 Mago, S., Sheremeta, R., and Yates, A. Best-of-Three Contests: Experimental Evidence.

10-21 Kimbrough, E. and Sheremeta, R. Make Him an Offer He Can't Refuse: Avoiding Conflicts Through Side Payments.

10-20 Savikhim, A. and Sheremeta, R. Visibility of Contributions and Cost of Inflation: An Experiment on Public Goods.

10-19 Sheremeta, R. and Shields, T. Do Investors Trust or Simply Gamble?

10-18 Deck, C. and Sheremeta, R. Fight or Flight? Defending Against Sequential Attacks in the Game of Siege. 
10-17 Deck, C., Lin, S. and Porter, D. Affecting Policy by Manipulating Prediction Markets: Experimental Evidence.

10-16 Deck, C. and Kimbrough, E. Can Markets Save Lives? An Experimental Investigation of a Market for Organ Donations.

10-15 Deck, C., Lee, J. and Reyes, J. Personality and the Consistency of Risk Taking Behavior: Experimental Evidence.

10-14 Deck, C. and Nikiforakis, N. Perfect and Imperfect Real-Time Monitoring in a Minimum-Effort Game.

10-13 Deck, C. and Gu, J. Price Increasing Competition? Experimental Evidence.

10-12 Kovenock, D., Roberson, B.,and Sheremeta, R. The Attack and Defense of Weakest-Link Networks.

10-11 Wilson, B., Jaworski, T., Schurter, K. and Smyth, A. An Experimental Economic History of Whalers' Rules of Capture.

10-10 DeScioli, P. and Wilson, B. Mine and Thine: The Territorial Foundations of Human Property.

10-09 Cason, T., Masters, W. and Sheremeta, R. Entry into Winner-Take-All and Proportional-Prize Contests: An Experimental Study.

10-08 Savikhin, A. and Sheremeta, R. Simultaneous Decision-Making in Competitive and Cooperative Environments.

10-07 Chowdhury, S. and Sheremeta, R. A generalized Tullock contest.

10-06 Chowdhury, S. and Sheremeta, R. The Equivalence of Contests.

10-05 Shields, T. Do Analysts Tell the Truth? Do Shareholders Listen? An Experimental Study of Analysts' Forecasts and Shareholder Reaction.

10-04 Lin, S. and Rassenti, S. Are Under- and Over-reaction the Same Matter? A Price Inertia based Account.

10-03 Lin, S. Gradual Information Diffusion and Asset Price Momentum.

10-02 Gjerstad, S. and Smith, V. Household expenditure cycles and economic cycles, 1920 - 2010.

10-01 Dickhaut, J., Lin, S., Porter, D. and Smith, V. Durability, Re-trading and Market Performance.

2009

09-11 Hazlett, T., Porter, D., Smith, V. Radio Spectrum and the Disruptive Clarity OF Ronald Coase.

09-10 Sheremeta, R. Expenditures and Information Disclosure in Two-Stage Political Contests. 
09-09 Sheremeta, R. and Zhang, J. Can Groups Solve the Problem of Over-Bidding in Contests?

09-08 Sheremeta, R. and Zhang, J. Multi-Level Trust Game with "Insider" Communication.

09-07 Price, C. and Sheremeta, R. Endowment Effects in Contests.

09-06 Cason, T., Savikhin, A. and Sheremeta, R. Cooperation Spillovers in Coordination Games.

09-05 Sheremeta, R. Contest Design: An Experimental Investigation.

09-04 Sheremeta, R. Experimental Comparison of Multi-Stage and One-Stage Contests.

09-03 Smith, A., Skarbek, D., and Wilson, B. Anarchy, Groups, and Conflict: An Experiment on the Emergence of Protective Associations.

09-02 Jaworski, T. and Wilson, B. Go West Young Man: Self-selection and Endogenous Property Rights.

09-01 Gjerstad, S. Housing Market Price Tier Movements in an Expansion and Collapse.

2008

08-10 Dickhaut, J., Houser, D., Aimone, J., Tila, D. and Johnson, C. High Stakes Behavior with Low Payoffs: Inducing Preferences with Holt-Laury Gambles.

08-09 Stecher, J., Shields, T. and Dickhaut, J. Generating Ambiguity in the Laboratory.

08-08 Stecher, J., Lunawat, R., Pronin, K. and Dickhaut, J. Decision Making and Trade without Probabilities.

08-07 Dickhaut, J., Lungu, O., Smith, V., Xin, B. and Rustichini, A. A Neuronal Mechanism of Choice.

08-06 Anctil, R., Dickhaut, J., Johnson, K., and Kanodia, C. Does Information Transparency Decrease Coordination Failure?

08-05 Tila, D. and Porter, D. Group Prediction in Information Markets With and Without Trading Information and Price Manipulation Incentives.

08-04 Caginalp, G., Hao, L., Porter, D. and Smith, V. Asset Market Reactions to News: An Experimental Study.

08-03 Thomas, C. and Wilson, B. Horizontal Product Differentiation in Auctions and Multilateral Negotiations.

08-02 Oprea, R., Wilson, B. and Zillante, A. War of Attrition: Evidence from a Laboratory Experiment on Market Exit.

08-01 Oprea, R., Porter, D., Hibbert, C., Hanson, R. and Tila, D. Can Manipulators Mislead Prediction Market Observers? 